\title{
Evaluation of the Hinge Moment and Normal Force Aerodynamic Loads from a Seamless Adaptive Compliant Trailing Edge Flap in Flight
}

\author{
Eric J. Miller, ${ }^{1}$ Josue Cruz, ${ }^{2}$ and Shun-Fat Lung ${ }^{3}$ \\ NASA Armstrong Flight Research Center, Edwards, California, 93523 \\ Sridhar Kota, Ph.D., ${ }^{4}$ Gregory Ervin, ${ }^{5}$ and Kerr-Jia Lu, Ph.D. ${ }^{6}$ \\ FlexSys Inc., Ann Arbor, Michigan, 48105 \\ and \\ Pete Flick ${ }^{7}$ \\ AFRL Air Vehicles Directorate, Wright-Patterson Air Force Base, Ohio, 45433
}

\begin{abstract}
A seamless adaptive compliant trailing edge (ACTE) flap was demonstrated in flight on a Gulfstream III aircraft (Gulfstream Aerospace Corporation, Savannah, Georgia) at the National Aeronautics and Space Administration (NASA) Armstrong Flight Research Center (Edwards, California). The trailing edge flap was deflected between $-2^{\circ}$ up and $+30^{\circ}$ down in flight. The safety-of-flight parameters for the ACTE flap experiment require that flap-to-wing interface loads be sensed and monitored in real time to ensure that the structural load limits of the wing are not exceeded. The attachment fittings connecting the flap to the aircraft wing rear spar were instrumented with strain gages and calibrated using known loads for measuring hinge moment and normal force loads in flight. The interface hardware instrumentation layout and load calibration are discussed. Twenty-one applied calibration test load cases were developed for each individual fitting. The 2-sigma residual errors for the hinge moment was calculated to be 2.4 percent, and for normal force was calculated to be 7.3 percent. The hinge moment and normal force generated by the ACTE flap with a hinge point located at 26-percent wing chord were measured during steady state and symmetric pitch maneuvers. The loads predicted from analysis were compared to the loads observed in flight. The hinge moment loads showed good agreement with the flight loads while the normal force loads calculated from analysis were overpredicted by approximately 20 percent. Normal force and hinge moment loads calculated from the pressure sensors located on the ACTE showed good agreement with the loads calculated from the installed strain gages.
\end{abstract}

\section{Nomenclature}

ACTE $=$ Adaptive Compliant Trailing Edge

AFRC $=$ Armstrong Flight Research Center

$\mathrm{AFRL}=$ Air Force Research Laboratory

AOA $=$ angle of attack

$\mathrm{BL} \quad=$ butt line

\footnotetext{
${ }^{1}$ Research Engineer, Aerostructures Branch, P.O. Box 273, Edwards, California, 93523, AIAA member.

${ }^{2}$ Research Engineer, Aerostructures Branch, P.O. Box 273, Edwards, California, 93523, AIAA member.

${ }^{3}$ Research Engineer, Aerostructures Branch, P.O. Box 273, Edwards, California, 93523, AIAA nonmember. ${ }^{4}$ President and CEO, FlexSys Inc., Ann Arbor, Michigan, 48105, AIAA nonmember.

${ }^{5}$ Operations Manager, FlexSys Inc., Ann Arbor, Michigan, 48105, AIAA nonmember.

${ }^{6}$ Principal Engineer, FlexSys Inc., Ann Arbor, Michigan, 48105, AIAA nonmember.

${ }^{7}$ Research Engineer, AFRL Air Vehicles Directorate, Wright-Patterson Air Force Base, Ohio, 45433, AIAA nonmember.
} 


$\begin{array}{ll}\mathrm{b}_{\mathrm{f}} & =\text { flap span, } 18.75 \mathrm{ft} \\ \mathrm{CFD} & =\text { computational fluid dynamics } \\ \mathrm{C}_{\mathrm{h}_{\mathrm{f}}} & =\text { ACTE flap aerodynamic hinge moment coefficient, } \frac{\mathrm{H}_{\mathrm{f}}}{\mathrm{qS}_{\mathrm{f}} \mathrm{f}} \\ \mathrm{C}_{\mathrm{N}_{\mathrm{f}}} & =\text { ACTE flap aerodynamic normal force coefficient, } \frac{\mathrm{N}_{\mathrm{f}}}{\mathrm{qS} \mathrm{S}_{\mathrm{f}}} \\ \mathrm{C}_{\mathrm{f}} & =\text { flap average chord, } 3.13 \mathrm{ft} \\ \mathrm{cg}_{\mathrm{f}} & =\text { center of gravity of the total flap modification weight aft of the flap hinge point } \\ \mathrm{FEM} & =\text { finite element method } \\ \mathrm{G}-\mathrm{III} & =\text { Gulfstream III } \\ \mathrm{H}_{\mathrm{f}} & =\text { ACTE flap aerodynamic hinge moment, in-lb } \\ \mathrm{IB} & =\text { inboard } \\ \mathrm{M} & =\text { Mach number } \\ \mathrm{NASA} & =\text { National Aeronautics and Space Administration } \\ \mathrm{N}_{\mathrm{f}} & =\text { ACTE flap aerodynamic normal force, } 1 \mathrm{~b} \\ \mathrm{n}_{\mathrm{z}} & =\text { airplane normal acceleration, } \mathrm{g} \\ \mathrm{OB} & =\text { outboard } \\ \mathrm{POPU} & =\text { pushover-pullup } \\ \mathrm{q} & =\text { free stream dynamic pressure, } \mathrm{lb} / \mathrm{ft}^{2} \\ \mathrm{SCRAT} & =\text { SubsoniC Research Aircraft Testbed } \\ \mathrm{S}_{\mathrm{f}} & =\text { flap panel area, } 58.8 \mathrm{ft}^{2} \\ \mathrm{TS} & =\text { transition surface } \\ \mathrm{W}_{\mathrm{f}} & =\text { total flap modification weight } \\ \mathrm{WUT} & =\text { wind-up turn } \\ \alpha & =\text { airplane angle of attack, deg }\end{array}$

\section{Introduction}

$\mathrm{F}$ ight-testing new and innovative structures in a flight-relevant environment promotes the transition of structural technologies from research to mainstream production. Wind-tunnel and ground-based load testing of structural flight technologies have inherent limitations that can be overcome through flight-testing. The National Aeronautics and Space Administration (NASA) Armstrong Flight Research Center (AFRC) (Edwards, California) has procured, modified, and instrumented a Gulfstream G-III airplane (Gulfstream Aerospace Corporation, Savannah, Georgia), to increase the Technology Readiness Level (TRL) of promising new flight technologies. This airplane is named the SubsoniC Research Aircraft Testbed (SCRAT). ${ }^{1}$

The NASA AFRC partnered with the Air Force Research Laboratory (AFRL) and FlexSys Inc. (Ann Arbor, Michigan) to flight test the Adaptive Compliant Trailing Edge (ACTE) experiment to demonstrate a seamless adaptive compliant structural control surface in flight. ${ }^{2}$ Wind-tunnel testing and small-scale flight tests of the compliant technology were conducted as a first step, but a full-scale compliant structure requires flight-testing to build confidence before the technology can be fully transitioned to commercial industry. ${ }^{3}$

The Mission Adaptive Wing (MAW) program in the 1980s demonstrated the benefits of seamless, morphing, wing leading and trailing edges on a modified F-111 airplane (General Dynamics); since then, many in the aviation research and development community have attempted to realize those benefits without the associated weight and complexity of the mechanism behind the MAW. ${ }^{4}$

Structural design optimization methods that produce a design for a structure that can bend and twist to achieve various wing shapes for optimum flight throughout the flight envelope are the key enabler for ACTE. The ACTE technology is envisioned as a multifunctional aerodynamic surface that enables the airfoil shape to be optimized for minimum drag over a broad range of flight conditions, instead of a single flight condition using traditional wing design. The ACTE is also envisioned to be actuated at high enough rates to enable structural load alleviation during maneuvers and gusts, leading to lighter-weight wing structures and more efficient aerodynamic vehicle configurations. The ACTE can also achieve large deflections for use in high-lift conditions. Contemporary aviation structures employ a system of mechanisms to mechanically actuate control surfaces. FlexSys Inc. technology takes advantage of material elasticity to produce large structural deformations while maintaining the structural strength required to carry the air loads.

Two ACTE flaps were fabricated and assembled to replace both existing Fowler flaps on the SCRAT. Figure 1 shows the ACTE flaps installed on the Gulfstream III SCRAT at a flap deflection of $20^{\circ}$. The primary objective of the 
flight-test program was structural flight demonstration of the ACTE technology. Demonstrating the ACTE technology within the envelope applicable to cruise drag reduction and gust load alleviation was deemed an additional requirement of this test program in order to demonstrate the versatility of this technology. The ACTE test program was structured to collect aerodynamic and structural performance data for assessment of the technology for future flight applications, so in-flight actuation was not required for this demonstration. The ACTE flaps were fixed at a predetermined deflection angle for each flight and remained fixed in that position for the duration of that flight. The flight-test deflection range of the ACTE was $-2^{\circ}$ to $+30^{\circ}$ (- signifies up-flap deflection, + signifies down-flap deflection). The ACTE was designed and operated to $-9^{\circ}$ and $+40^{\circ}$ on the ground.

\section{Compliant Design}

The ACTE structure makes use of compliant design. ${ }^{5}$ When comparing human-engineered machines to systems found in nature, we observe fundamental differences in composition, work, and performance. Most engineered systems that transmit mechanical motions or forces or energy consist of a plurality of rigid components connected by various interfaces or joints. Engineered artifacts such as engines, pumps, propellers, wings, et cetera, have fixed geometry optimized for peak performance at a specific operating condition. Designs in nature, such as tree branches, bird wings, elephant trunks, and invertebrates, which account for a majority of all living creatures, are suitably compliant (flexible), comparatively strong, and offer a tremendous range of shape adaptation to dynamically maximize their performance.

Compliant design embraces elasticity, rather than avoiding it, to create one-piece kinematic machines, or joint-less mechanisms, that are strong and flexible (for shape adaptation). In common, flexural joints or flexures are concentrated at localized zones, sometimes along a single axis, surrounded by relatively rigid sections. These zones of high stress concentration limit the load-carrying capacity of systems with flexural joints. Distributed compliance is the ability of a structural system to be simultaneously flexible and strong - two quantities that are usually considered contradictory to each other in traditional engineering disciplines. Designs with distributed compliance exhibit both strength and flexibility, because every section of the material participates in both load-sharing and kinematic functions. The cascading benefits of elastic design include high fatigue life and a significant reduction in parts and mechanical complexity. Elimination of joints improves precision and eliminates friction and wear.

The concept of distributed compliance and its associated design methods were developed by Sridhar Kota of the University of Michigan. By combining the principles of continuum mechanics and kinematics, FlexSys Inc. developed algorithms for synthesizing lightweight compliant structures that have high (static and fatigue) strength and are sufficiently flexible to deliver a desired kinematic or shape-morphing function. ${ }^{6}$

The compliant iris mechanism developed by FlexSys Inc. shown in Fig. 2 demonstrates the concept of distributed compliance. The actuation energy supplied by simply rotating the external tabs (one clockwise, the other counterclockwise) is distributed more or less uniformly as strain energy. Large deformations can be achieved by subjecting every section of the material to contribute equally to the (shape-morphing) objective while all components share the loads. Every section of the material thus undergoes a very small amount of linear elastic strain with very low stress; therefore, the structure can undergo large deformations with high fatigue life.

The design of the FlexFoil ${ }^{\mathrm{TM}}$ (FlexSys Inc.) ACTE is based on these principles of compliant design. The ACTE distributes compliance throughout the structure, changing the wing camber from $-9^{\circ}$ to $+40^{\circ}$ on demand while sustaining the required external load. The FlexFoil ${ }^{\mathrm{TM}}$ variable-geometry surface uses the natural flexibility of aerospace-grade materials arranged in a joint-less skeletal configuration to continuously reshape its external form by using internal actuators. Each section of the internal compliant structure is optimized to share the external load and undergoes the specified deformation without overstressing any part of the structure. This "distributed compliance" enables large deformations with very low stresses so that the system can be cycled thousands of times without failure.

\section{Structural Composition}

The ACTE structure consists of four components. The main flap spans 168 inches and is the main lifting surface. The inboard and outboard transition surfaces each span 24 inches and blend the main flap structure into the inboard and outboard wing structure. Closeout panels were added around the ACTE boundary to create the seamless structure. All four components are shown in Fig. 3. The main flap, transition sections, and closeout structure are all contributing to the flap hinge moment and normal force loads.

The ACTE flaps were attached to the wing rear spar at the existing four Fowler flap attachment points on each wing. The existing G-III Fowler flaps are actuated aft and down using rollers guided by the four tracks attached to the rear spar of the wing. The ACTE integration required that the G-III flight and ground spoilers be removed to make room for the ACTE structure. The ACTE modification required the four Fowler flap tracks to be removed and replaced 
with the wing interface fittings that attach each ACTE flap to each G-III wing rear spar. A secondary spar was used to attach the ACTE main flap and transition structure to the four attachment points. The secondary spar minimized the amount of modification required to the G-III for integrating the ACTE. A cross section view of the interface structure is shown in Fig. 4.

All ACTE loads were transferred into the wing box through the four wing interface fittings. All closeout structure is attached to the ACTE structure, minimizing additional load transfer paths into the wing box structure. The interface fittings are labeled in Fig. 5. The inboard wing interface fitting is referenced as fitting A, proceeding outboard to fitting $\mathrm{D}$, which is closest to the aileron. The four interface fittings must constrain all three directions of motion of the ACTE flap, but maintain adequate translational and rotational freedom to allow ACTE lateral movement and wing flex reactions. Wing interface fittings $\mathrm{A}, \mathrm{B}$, and $\mathrm{C}$ allowed lateral span-wise movement. Interface fitting $\mathrm{D}$ constrained the span-wise motion of the ACTE flap, as does the G-III Fowler flap interface.

The interface fittings were made from 4340 steel that was heat-treated to $200 \mathrm{ksi}$ as required for meeting design strength requirements. The forward end of each interface fitting matched the original production Fowler flap fitting design, but the aft portion of each fitting was redesigned to interface with the new ACTE clevis fittings. All new hardware was designed to a required AFRC (no proof test) factor of safety of 2.25 on ultimate strength, while all existing G-III aircraft interfaces were shown to have positive margin to the original production airplane design factor of safety of 1.5 .

The ACTE mounting brackets attachment to the rear spar consisted of a main lug and upper attachment for reacting out the flap interface loads. The main lug is shown in Figure 5 and is located at approximately 26 percent of wing chord. The flap hinge moment and normal force loads were reacted about the main lug on each interface fitting. The total normal force load was calculated as a summation of the normal force loads from each fitting. The total hinge moment load was calculated similarly. The hinge moment load is consistent with typical control surface loads in which negative loads are caused by positive flap deflections.

\section{Instrumentation and Calibration}

The four interface fittings on each wing were instrumented with metallic foil strain gages and calibrated separately in a ground-test fixture in the Armstrong Flight Loads Laboratory (FLL). ${ }^{7}$ The load calibration methods utilized for this project are consistent with proven methods used on past projects at AFRC. ${ }^{8,9}$ The shear bridges are Vishay CEA-06-250US-350 strain gages (Vishay Intertechnology, Inc., Malvern, Pennsylvania; specifically, Micro-Measurements, Raleigh, North Carolina) and are located on the interface fitting web. Two tee rosettes were placed on the top and bottom flanges of each interface fitting to comprise the axial and bending bridge response. The tee rosettes are Vishay part number WK-06-125TB-10C/W strain gages. Each pair of rosettes (top and bottom) was configured in a full bridge configuration. The bending gages are Vishay part number WK-06-125PC-10C/W. A four-active-arm Wheatstone bridge configuration was chosen for all sensors to minimize thermal effects. ${ }^{10}$ Figure 6 shows the instrumented wing interface fittings A (left) and B (right).

The orientation and locations of the strain gages were determined based on finite element method (FEM) strain predictions in the interface fittings in order to give an adequate calibration result. The center of each shear bridge was located on the neutral axis of each interface fitting and oriented perpendicular to or parallel with a nearby flange for ease of installation. The tee rosettes and linear pattern gages were aligned on center, with the shear gage on the inside of the upper and lower flanges. The gages were installed on the inner flanges to protect them from abuse during installation and actuation of the flap. The strain-gage bridge locations were selected on each interface fitting to avoid fillets and geometry that could hinder the strain response of the bridge.

The interface fitting surface was prepared by baking it for $1 \mathrm{hr}$ at $275{ }^{\circ} \mathrm{F}$. The adhesive M-Bond 600 (Micro-Measurements) was used and was cured for $2 \mathrm{hr}$. The sealants M COAT-A (Micro-Measurements) and M COAT-D (Micro-Measurements) were applied, followed by a final coat of MIL-S-8802 sealant to protect the strain gage from the environment. Interbridge wiring was 32-gauge. Shielded four-conductor aircraft wire was used for the leadwire from the solder tabs to the Teletronics Technology Corporation (TTC) (Newtown, Pennsylvania) boxes.

The ACTE project team decided to design a dedicated load fixture for calibration of the wing interface fittings. Hinge moment, normal force, and axial loads were applied to each fitting to derive acceptable normal force and hinge moment equations. The applied loads were scaled depending on the structural limits of each interface fitting. The interface fitting load calibration reaction frame is shown in Fig. 7. Three hydraulic actuators were used to apply the calibration loads. A total of 21 separate load cases were applied to each fitting. A subset of the load cases was used for deriving load equations, while a few cases were excluded from the calibration set and used for validation of the derived load equations. The BALFIT ${ }^{11}$ software tool, developed at the NASA Ames Research Center (Moffett Field, California), was utilized to determine which mathematical model coefficient to use for the calibration. The 2-sigma 
errors for each fitting are shown in Fig. 8. Both the calibration set and validation errors are shown. The goal of the calibration was to obtain normal force errors under 10 percent and hinge moment errors under 5 percent for the validation cases. These errors were determined based on previous experience with strain-gage calibrations. The validation case 2-sigma residual errors for the hinge moment was calculated to be 2.4 percent, and for normal force was calculated to be 7.3 percent.

The interface fitting strain-gage-derived load equations were zeroed once the fittings were installed onto the airplane, but before the ACTE flap was installed to the fittings. The summation of the loads from the four interface fittings recorded on the ground represented the total flap modification weight. The total flap modification weight includes the ACTE structure, closeout panels, and installed instrumentation hardware. Once the ACTE was installed onto the airplane, additional check cases were performed to assess the total flap loads. The check-loading tests made use of shot bags and applied loads from an aircraft jack with an attached load pad. The total normal force error was calculated to be under 10 percent and the total bending or hinge moment load was calculated to be under 5 percent.

The SCRAT airplane instrumentation system collects data from sensors positioned throughout the airplane. The data are recorded onboard and transmitted to the ground for real-time monitoring in the control room. The airplane instrumentation system has 16-bit resolution, allowing adequate range and resolution in the measurements. The instrumentation system is configured for monitoring approximately 6000 parameters at a range of 1 to 20,000 samples per second. The interface fitting loads will be monitored at 500 samples per second to collect any dynamic response in the structure. Previous wing strain-gage data recorded during the SCRAT baseline flights show minimal noise. Flight condition information in addition to the strain-gage and pressure-port-sensor data were collected at each flight condition. The measurement errors in the flight condition data propagate into the flight data hinge moment and normal force results. The associated flight condition measurement errors are shown in Table 1 . The accuracies are based on the measurement uncertainty in the instrumentation hardware.

Table 1. Estimated accuracies of measured flight parameter quantities.

\begin{tabular}{|l|l|}
\hline Flight parameter & Estimated accuracy \\
\hline $\mathrm{M}$ & $+/-0.004$ \\
\hline $\mathrm{q}, \mathrm{lb} / \mathrm{ft}^{2}$ & $+/-2 \mathrm{lb} / \mathrm{ft}^{2}$ \\
\hline $\mathrm{n}_{\mathrm{z}}, \mathrm{g}$ & $+/-0.02 \mathrm{~g}$ \\
\hline$\alpha, \mathrm{deg}$ & $+/-0.26^{\circ}$ \\
\hline
\end{tabular}

\section{Flight-Test Discussion}

The ACTE design flight envelope was based on the G-III Fowler flap operational envelope. A goal for the ACTE test program was to fly beyond the limits of the G-III Fowler flap extension limits, which determined the additional ACTE flap settings and airspeed limits. The ACTE flap operational limit airspeeds, along with the ACTE design airspeeds, are shown in Table 2. The ACTE flight envelope is shown in Fig. 9 with the corresponding Mach limits for each set of flap positions. Figure 9 shows the design goals for each flap deflection, which correspond to the maximum Mach and dynamic pressure test conditions. Research points were distributed over the envelope for collecting steady-state and aerodynamic data. Loads points at 10,000-ft altitude Mach 0.3, 0.4, and 0.5 were executed for assessing the individual flap deflections against each other at a consistent dynamic pressure. The corresponding dynamic pressures for Mach 0.3, 0.4, and 0.5 were 92 psf, 163 psf, and 255 psf respectively. Pushover-pullup (POPU) and wind-up turn (WUT) maneuvers were flown to collect load data over a range of normal acceleration load factors and angles of attack. Both maneuvers were flown up to a $2.0-\mathrm{g}$ limit.

Table 2. Adaptive Compliant Trailing Edge operational limit and design airspeeds.

\begin{tabular}{|c|c|c|}
\hline $\begin{array}{c}\text { ACTE } \\
\text { flap position }\end{array}$ & $\begin{array}{c}\text { Airspeed } \\
\text { operational limit }\end{array}$ & $\begin{array}{c}\text { Design airspeeds } \\
(+15 \text { kn gust })\end{array}$ \\
\hline deg & kn & kn \\
\hline 2 & 340 & 355 \\
\hline 5 & 300 & 315 \\
\hline 15 & 250 & 265 \\
\hline 30 & 170 & 185 \\
\hline
\end{tabular}


Although the ACTE structure was designed for a flap deflection range up to $+40^{\circ}$ down, the flight demonstration was held to a maximum deflection of $+30^{\circ}$ because the flap would be exposed to fully-separated flow at that point, negating any additional benefit of collecting additional aerodynamic data. The up-flap deflections were capable of $-9^{\circ}$ but were limited to $-2^{\circ}$ due to the takeoff restrictions of the G-III. Research test points were distributed over the envelope for collecting steady-state trim points and maneuvering data for each flap deflection.

The ACTE flaps were flown to a maximum airspeed of 340 knots calibrated airspeed (KCAS) and Mach .75. The altitude was limited to $40,000 \mathrm{ft}$ to minimize testing requirements. The stall limit was based on flap setting and airplane gross weight. A range of maneuvers were flown at each test point, including doublets and raps in all three axes, pushover-pullups and wind-up turns. The airplane was limited to a normal acceleration of $0 \mathrm{~g}$ to $2.0 \mathrm{~g}$.

The flap total normal force and total hinge moment loads were a summation of the loads at the four attachment fittings. The hinge moment and normal force loads recorded during flight represent a net load that includes aerodynamic and inertial loads. The total aerodynamic loads were converted to coefficient form using the dynamic pressure, $\mathrm{q}$, flap surface area, $\mathrm{S}_{\mathrm{f}}$, and flap chord, $\mathrm{c}_{\mathrm{f}}$. The inertial loads were developed from the total flap modification weight, $\mathrm{W}_{\mathrm{f}}$, flap center of gravity, $\mathrm{cg}_{\mathrm{f}}$, and aircraft normal acceleration, $\mathrm{n}_{\mathrm{z}}$. The approach taken in this paper for correcting the measured net flap hinge moment and normal force loads for inertial load effects is shown in Eqs. 1 and 2.

$$
\begin{gathered}
\mathrm{C}_{\mathrm{h}_{\mathrm{f}}}=\left(\mathrm{H}_{\mathrm{f}}+\mathrm{n}_{\mathrm{z}} \mathrm{W}_{\mathrm{f}} \mathrm{cg}_{\mathrm{f}}\right) / \mathrm{qS}_{\mathrm{f}} \mathrm{c}_{\mathrm{f}} \\
\mathrm{C}_{\mathrm{N}_{\mathrm{f}}}=\left(\mathrm{N}_{\mathrm{f}}+\mathrm{n}_{\mathrm{z}} \mathrm{W}_{\mathrm{f}}\right) / \mathrm{qS} \mathrm{S}_{\mathrm{f}}
\end{gathered}
$$

The loads from both left and right flaps were assessed for trends and compared to analysis. The loads overall were consistent for both flaps. The average of both flaps appeared to smooth the data. The hinge moment and normal force loads are only shown for the right flap for all data figures. All flight conditions shown in this report are contained in Table 3.

Table 3. Adaptive Complaint Trailing Edge flight conditions.

\begin{tabular}{|c|c|c|}
\hline \multirow{2}{*}{ ACTE setting } & Mach & Altitude, $\mathrm{ft}$ \\
\hline-2 & $0.30,0.40,0.50$ & 10,000 \\
\hline-2 & 0.65 & 20,000 \\
\hline 0 & $0.30,0.40,0.50,0.60$ & 10,000 \\
\hline 0 & 0.75 & 21,200 \\
\hline 2 & $0.30,0.40,0.50,0.60$ & 10,000 \\
\hline 2 & 0.75 & 21,200 \\
\hline 5 & $0.30,0.40,0.50$ & 10,000 \\
\hline 5 & 0.75 & 30,000 \\
\hline 5 & 0.65 & 20,000 \\
\hline 10 & $0.30,0.40$ & 10,000 \\
\hline 10 & 0.55 & 20,000 \\
\hline 12.5 & 0.40 & 10,000 \\
\hline 12.5 & 0.55 & 20,000 \\
\hline 15 & $0.30, .40$ & 10,000 \\
\hline 15 & 0.55 & 20,000 \\
\hline 17.5 & 0.30 & 10,000 \\
\hline 17.5 & 0.38 & 20,000 \\
\hline 20 & 0.30 & 10,000 \\
\hline 20 & 0.38 & 20,000 \\
\hline 25 & 0.30 & 10,000 \\
\hline 25 & 0.38 & 20,000 \\
\hline 30 & 0.30 & 10,000 \\
\hline 30 & 0.38 & 20,000 \\
\hline & & \\
\hline
\end{tabular}




\section{Analysis Load Calculations}

The ACTE hinge moment and normal force loads were calculated using a combination of computational fluid dynamics (CFD) and FEM codes. Computational fluid dynamics simulations using Cmarc (AeroLogic, Los Angeles, California) ${ }^{12}$; TRANAIR (Calmar Research Corporation, Cato, New York) ${ }^{13}$; and STAR-CCM ${ }^{\circledR}$ (CD-adapco, Melville, New York) ${ }^{14}$ CFD codes were performed to predict the pressure distribution on the flap surface with different flight conditions. The Cmarc program, a lower-level inviscid panel code, has been a useful tool for assessing loads on subsonic aircraft. The TRANAIR CFD code can model minor flow separation and can vary the trim angle to match a specified lift coefficient; TRANAIR uses a structured grid. The STAR-CCM $+{ }^{\circledR}$ code is a full Navier-Stokes CFD code that uses an unstructured grid. The STAR-CCM $+{ }^{\circledR}$ code is the only code capable of modeling the separated flow at the $30^{\circ}$ flap deflection. It was observed from FEM analysis that the summation of the flap normal force loads on the four attachment fittings is negligible; only pressure distribution on the flap is needed to calculate the loads on the fittings due to aerodynamic loads. The Cmarc and TRANAIR analysis codes were used for the lower flap deflections of $-2^{\circ}$ to $15^{\circ}$, where the flow separation would be minimal; STAR-CCM $+{ }^{\circledR}$ CFD was used for flap deflections of $15^{\circ}$ and above, where flow separation over the flap was expected.

The analysis was performed in two phases. The first phase consisted of analysis predictions from TRANAIR and STAR-CCM $+{ }^{\circledR}$ pressures applied to the G-III wing / ACTE FEM model to derive interface hinge moment and normal force loads. The second phase took place after the flight phase and consisted of using Cmarc and TRANAIR codes using the as-flown airplane gross weight for matching the airplane lift coefficient. Table 4 shows the flap position, analysis method, and corresponding flight condition for the phase 1 preflight analysis predictions.

Table 4. Phase 1 Adaptive Compliant Trailing Edge flap preflight analysis predictions.

\begin{tabular}{|c|c|c|}
\hline Flap position & Analysis method & Flight condition \\
\hline 0 & TRANAIR to FEM & Mach 0.40 altitude $10,000 \mathrm{ft}$ \\
\hline 2 & TRANAIR to FEM & Mach 0.40 altitude $10,000 \mathrm{ft}$ \\
\hline 5 & TRANAIR to FEM & Mach 0.40 altitude $10,000 \mathrm{ft}$ \\
\hline 10 & TRANAIR to FEM & Mach 0.40 altitude $10,000 \mathrm{ft}$ \\
\hline 15 & TRANAIR to FEM & Mach 0.40 altitude $10,000 \mathrm{ft}$ \\
\hline 15 & STAR-CCM $+{ }^{\circledR}$ to FEM & Mach 0.40 altitude $10,000 \mathrm{ft}$ \\
\hline 20 & STAR-CCM $+{ }^{\circledR}$ to FEM & Mach 0.30 altitude $10,000 \mathrm{ft}$ \\
\hline 25 & STAR-CCM $+{ }^{\circledR}$ to FEM & Mach 0.30 altitude $10,000 \mathrm{ft}$ \\
\hline 30 & STAR-CCM $+{ }^{\circledR}$ to FEM & Mach 0.30 altitude $10,000 \mathrm{ft}$ \\
\hline
\end{tabular}

The preflight analysis conditions were run at two angles of attack. The TRANAIR analysis code calculated angles of attack for a 58,000-lb gross weight airplane aircraft trimmed at $1.0 \mathrm{~g}$ and $2.0 \mathrm{~g}$ normal acceleration. The STAR-CCM $+{ }^{\circledR}$ analysis cases were completed at an angle of attack of $0.0^{\circ}$ and $8.0^{\circ}$, which bounded the analysis conditions. The pressure distribution from the CFD analysis grids were then interpolated to the structural FEM grid for structural analysis. It would have been possible to integrate the loads directly from the CFD codes, but the ACTE project team wanted to verify the structural strength for each individual interface fitting for the flight-testing program. The only way to do that was by using a finite element model with representative stiffness properties of the wing and ACTE structures. The $15^{\circ}$ flap deflection was run using both STAR-CCM $+{ }^{\circledR}$ and TRANAIR so that the differences in flow separation modeling could be assessed.

The flap hinge moment and normal force loads on the four attachment fittings were calculated using finite element simulation. The finite element model of the G-III wing containing 1519 nodes and 1920 elements in MSC Nastran ${ }^{\mathrm{TM}}$ (MSC Software, Newport Beach, California) ${ }^{15}$ format was built at NASA AFRC based on the Gulfstream Aerospace Corporation proprietary stress report. In this stress report, the coordinates and thickness of each panel on the top and bottom surfaces of the wing were given. The ACTE flap finite element model containing 44060 nodes and 66300 elements was created by FlexSys Inc. in ANSYS ${ }^{\circledR}$ (ANSYS, Inc., Canonsburg, Pennsylvania) ${ }^{16}$ format and delivered to NASA AFRC in MSC Nastran ${ }^{\text {TM }}$ format. The ACTE flap model was then connected to the G-III wing model using MSC Nastran ${ }^{\text {TM }}$ CBUSH elements. Figure 10 depicts the finite element model of the G-III wingbox with the attached ACTE flap. The total hinge moment and normal force loads were calculated from summing up the loads from each individual interface fitting. The total loads were interpolated to match the aircraft angle of attack in flight. The analysis aerodynamic loads were converted to coefficient form using the dynamic pressure and flap geometry.

The post-flight analysis was conducted using the Cmarc and TRANAIR codes as a model validation exercise. The pressure loads were derived from models that were trimmed based on aircraft gross weight, unlike the models used in 
the first phase that were trimmed to a maximum aircraft gross weight. Table 5 shows the flap position, analysis code, and corresponding flight condition for the phase 2 post-flight analysis correlation. No FEM model was used for phase 2. The pressures on the surface of the model were integrated together to calculate the interface hinge and normal force loads on the flap.

Table 5. Phase 2 Adaptive Compliant Trailing Edge flap post-flight analysis cases.

\begin{tabular}{|c|c|c|}
\hline Flap position & Analysis code & Flight condition \\
\hline 0 & TRANAIR and Cmarc & Mach 0.30 altitude $10,000 \mathrm{ft}$ \\
\hline 0 & TRANAIR and Cmarc & Mach 0.40 altitude $10,000 \mathrm{ft}$ \\
\hline 0 & TRANAIR and Cmarc & Mach 0.50 altitude $10,000 \mathrm{ft}$ \\
\hline 5 & TRANAIR and Cmarc & Mach 0.30 altitude $10,000 \mathrm{ft}$ \\
\hline 5 & TRANAIR and Cmarc & Mach 0.40 altitude $10,000 \mathrm{ft}$ \\
\hline 5 & TRANAIR and Cmarc & Mach 0.50 altitude $10,000 \mathrm{ft}$ \\
\hline 15 & TRANAIR and Cmarc & Mach 0.30 altitude $10,000 \mathrm{ft}$ \\
\hline 15 & TRANAIR and Cmarc & Mach 0.40 altitude $10,000 \mathrm{ft}$ \\
\hline 15 & TRANAIR and Cmarc & Mach 0.50 altitude $20,000 \mathrm{ft}$ \\
\hline
\end{tabular}

\section{Results and Discussion}

\section{A. Adaptive Compliant Trailing Edge Interface Hinge Moment}

The flap interface hinge moment loads were collected over a flap range of $-2^{\circ}$ to $+30^{\circ}$. The hinge moment loads are plotted against angle of attack in Fig. 11. A least-squares fit line is shown for each flap deflection. The data were taken from WUT and POPU maneuvers. The hinge moment coefficient reaches maximum at approximately -.45 for a $30^{\circ}$ flap deflection. The hinge moment data are taken from test conditions at Mach numbers 0.3 and 0.4 and an altitude of 10,000 ft. The hinge moment coefficient is plotted versus ACTE flap deflection in Fig. 12 for four different angles of attack. The data from figure 11 were extrapolated to the angles of attack of $-4^{\circ}$ and $+8^{\circ}$ to create Fig. 12. It is important to point out that there is very little load buildup during maneuvers as compared to the load increment increase encountered during increases in flap deflection and airspeed. The slopes of the hinge moment loads plotted in Fig. 11 change sign at a flap deflection of $17^{\circ}$ due to flow separation over the flap; this phenomenon is highlighted clearly by the intersection of loads in Fig. 12.

The analysis predictions for hinge moment loads compared to the flight hinge moment loads for equivalent flight conditions are shown in Fig. 13. The analysis used the flight trim angles of attack for comparing the hinge moment loads. The analytical calculations for hinge moment from phase 1 at the intermediate flap angles of $10^{\circ}$ and $15^{\circ}$ overpredicted the loads compared to the flight hinge moment loads predicted from phase 2 . The difference is for the most part attributed to the methods used for interpolating the pressures to the FEM model and integration of the loads. This result is good from a structural design standpoint in that the structure has extra margin built into it because the load prediction was conservative. The phase 2 results show a slightly better correlation to the flight results than do the result from phase 1, which could be attributed to an improved matching of aircraft gross weight and lift coefficient post-flight. No FEM model was used, which eliminates one additional source of error that was introduced during the first phase. Figure 14 shows a plot of the hinge moment per degree of angle of attack for analysis conditions and equivalent flight conditions. The agreement overall is adequate given the low load response observed during the maneuver.

Additional hinge moment coefficients were calculated at the additional anchor points and maximum Mach number and dynamic pressures for each flap deflection; those results are plotted in Fig. 15. The higher flap deflections have a smaller envelope and less scatter should be expected in those results.

\section{B. Adaptive Compliant Trailing Edge Interface Normal force}

The flap interface normal force loads were collected over a flap range of $-2^{\circ}$ to $+30^{\circ}$. The normal force loads are plotted against angle of attack in Fig. 16. The normal force coefficient reaches maximum at approximately .85 for a flap deflection of $30^{\circ}$. The normal force data are taken from test conditions at Mach numbers 0.3 and 0.4 and an altitude of 10,000 ft. The normal force coefficient is plotted versus ACTE flap deflection in Fig. 17 for four different angles of attack. Very similar trends as observed in the hinge moment data are observed for the normal force loads in flight. Just as was observed within the hinge moment results, there is very little normal force load buildup during maneuvers as compared to the load increment increase encountered during increases in flap deflection and airspeed. 
The analysis predictions for normal force loads compared to the flight normal force loads for equivalent flight conditions are shown in Fig. 18. The analysis used the flight trim angles of attack for comparing the normal force loads. The normal force analytical calculations overpredict the normal force by approximately 20 percent, verifying that the structure contains more margin on structural strength than what was previously expected. There are a number of reasons for the discrepancy between analytical and flight results: low shear strain-gage response, inertial load errors, hysteresis in the interface structure, and CFD errors due to flow separation.

The slopes of the normal force coefficient per degree of angle of attack are shown in Fig. 19. The slopes of the normal force per degree angle of attack are constant up to $15^{\circ}$ of flap deflection, and then decrease to zero for flap deflections of $20^{\circ}$ to $30^{\circ}$. The normal force per degree of angle of attack flight to analysis comparison is better for lower flap deflections than larger flap deflections. The overall correlation is poor, but the analysis does capture the overall flight data trend.

\section{Adaptive Compliant Trailing Edge Interface Fitting Reaction Loads}

The hinge moment and normal force loads were measured from each individual interface fitting. The geometry of the ACTE cross-section is shown in Fig. 5. The hinge moment is negative for positive flap deflections to stay consistent with the loads reported in this report. The distribution of loads into the wing rear spar were monitored in real time in flight to verify that each interface fitting stayed below its specific structural strength limit. Two different cases were analyzed to assess the wing flex interaction between the ACTE and wing structures. Tables 6 and 7 show the hinge moment and normal force measured at each interface fitting during a POPU maneuver for ACTE flap deflections of $5^{\circ}$ and $15^{\circ}$. The largest loads are shown on interface fittings A and B. Very little load is observed for interface fitting D. The normal force and bending moment trends are consistent between flight and analysis.

Table 6. Adaptive Compliant Trailing Edge $5^{\circ}$ interface fitting reaction load per $\mathrm{g}$ of normal acceleration due to wing flex.

\begin{tabular}{|c|c|c|c|c|c|c|}
\hline & \multicolumn{2}{|c|}{ ACTE analysis } & \multicolumn{2}{c|}{ Left ACTE flight } & \multicolumn{2}{c|}{ Right ACTE flight } \\
\hline Fitting & $\begin{array}{c}\text { Normal } \\
\text { force, } \\
\mathrm{lb}\end{array}$ & $\begin{array}{c}\text { Hinge } \\
\text { moment, } \\
\text { in-lb }\end{array}$ & $\begin{array}{c}\text { Normal } \\
\text { force, } \\
\mathrm{lb}\end{array}$ & $\begin{array}{c}\text { Hinge } \\
\text { moment, } \\
\text { in-lb }\end{array}$ & $\begin{array}{c}\text { Normal } \\
\text { force, } \\
\mathrm{lb}\end{array}$ & $\begin{array}{c}\text { Hinge } \\
\text { moment, } \\
\text { in-lb }\end{array}$ \\
\hline A & -896 & 9221 & -570 & 7252 & -670 & 8656 \\
\hline B & 1401 & -7416 & 730 & -8834 & 747 & -8999 \\
\hline C & -109 & 87 & -110 & 2086 & -244 & 1466 \\
\hline D & -396 & 2978 & -19 & 1361 & -15 & 1579 \\
\hline Total & 0 & 4870 & 30 & 1864 & -182 & 2702 \\
\hline
\end{tabular}

Table 7. Adaptive Compliant Trailing Edge $15^{\circ}$ interface fitting reaction load per $\mathrm{g}$ of normal acceleration due to wing flex.

\begin{tabular}{|c|c|c|c|c|c|c|}
\hline & \multicolumn{2}{|c|}{ ACTE analysis } & \multicolumn{2}{c|}{ Left ACTE flight } & \multicolumn{2}{c|}{ Right ACTE flight } \\
\hline Fitting & $\begin{array}{c}\text { Normal } \\
\text { force, } \\
\mathrm{lb}\end{array}$ & $\begin{array}{c}\text { Hinge } \\
\text { moment, } \\
\text { in-lb }\end{array}$ & $\begin{array}{c}\text { Normal } \\
\text { force, } \\
\mathrm{lb}\end{array}$ & $\begin{array}{c}\text { Hinge } \\
\text { moment, } \\
\text { in-lb }\end{array}$ & $\begin{array}{c}\text { Normal } \\
\text { force, } \\
\mathrm{lb}\end{array}$ & $\begin{array}{c}\text { Hinge } \\
\text { moment, } \\
\text { in-lb }\end{array}$ \\
\hline A & -739 & 7867 & -673 & 7991 & -781 & 9672 \\
\hline B & 1136 & -6957 & 828 & -11680 & 855 & -11188 \\
\hline C & -52 & -733 & -151 & 1701 & -204 & 297 \\
\hline D & -345 & 2910 & -93 & 2321 & -38 & 1844 \\
\hline Total & 0 & 3087 & -89 & 333 & -168 & 625 \\
\hline
\end{tabular}

\section{Adaptive Compliant Trailing Edge Interface Fitting Strain Gage versus Pressure Sensor Normal Force}

Static pressure sensors were installed on the upper and lower ACTE flap surface at three spanwise locations. The pressure sensors included in this analysis were attached to both the upper and lower surface of the main flap and upper and lower closeout panels. The closeout panels are attached to the secondary spar and thus those loads contribute to the overall hinge moment and normal force loads measured through the interface fittings. There were nine pressure sensors at each spanwise location on the lower surface and eight pressure sensors at each spanwise location on the 
upper surface. Each strip of sensors was multiplied by its corresponding area, dynamic pressure, and the vertical component of the normal surface vector. The loads at each upper and lower surface strip were multiplied by a spanwise length. Two specific flap geometries were used to average the normal force load to account for the loss of load in the transition sections. The two areas are shown in Fig. 20, where Area 1 represents the loads as if the entire flap surface (including transition surfaces) were generating a uniform pressure, and Area 2 represents the loads as if only the main flap is generating load. The average of the pressure surface load was converted to coefficient form using the same values used for converting the strain-gage loads to coefficients.

The comparison of strain-gage bridge normal force coefficient and the load from the pressure sensors are shown in Fig. 21. The integrated loads from Area 1 and Area 2 bound the flight data normal force. The integrated pressures along with the strain-gage normal force are plotted along with the CFD analysis normal force in Fig. 22. The CFD is predicting a normal force greater than the load produced from Area 1. This is representative of what is observed from looking at the flap pressure coefficient (Cp) butt line (BL) plots comparisons.

The comparison of strain-gage bridge hinge moment coefficient and the load from the pressure sensors are shown in Fig. 23. The integrated loads from Area 1 and Area 2 bound the flight data hinge moment. The integrated pressures along with the strain-gage hinge moment are plotted along with the CFD analysis hinge moment in Fig. 24. The CFD is predicting a hinge moment that compares better to the flight data than that predicted for the normal force. It is observed for both the normal force and hinge moment comparisons that the strain-gage loads are larger than the averaged pressure sensor loads. The calculation of the average pressure sensor loads could be biased to better match the strain-gage loads for future flight load measurement efforts.

\section{Conclusions}

The hinge moment and normal force loads collected from a seamless adaptive compliant trailing edge (ACTE) flap in flight have been presented. The flap was fixed on the ground and flown between flap deflections of $-2^{\circ}$ to $+30^{\circ}$ over a range of flight conditions. The ACTE interface structure geometry, instrumentation layout, calibration test design, and analysis procedures were discussed. Steady state and symmetric pitch maneuvers were conducted at analysis points and at maximum allowable dynamic pressure points to capture the hinge moment and normal force loads on the ACTE flap. Comparisons with analytical predictions were shown. The following conclusions were drawn from this work:

- The ACTE technology on the GIII SCRAT was not optimized for maximum aerodynamic load benefit, it was mainly a structural demonstration project, but future clean sheet designs will be able tailor the structure for maximum aerodynamic load advantage.

- The hinge moment and normal force loads generated at ACTE flap positions above $15^{\circ}$ plateaued due to flow separation and were lower than the loads generated by a typical Fowler flap that creates a gap in the structure for energizing the flow over the flap.

- The interface fittings in general do not lend themselves to ample bridge response given the large design factors of safety and the short, stubby nature of the flight fittings, but the resulting flight data were sufficient for flight monitoring and analysis comparisons.

- The Cmarc panel code and TRANAIR code produced identical results for flap positions up to $15^{\circ}$ where flow separation was observed.

- Cmarc is a time efficient CFD code as compared to TRANAIR, thus future work will make use of the Cmarc code more significantly for flap positions up to $15^{\circ}$.

- The extensive flow separation at flap positions above $15^{\circ}$ require the use of a full Navier-Stokes CFD code such as StarCCM+.

- Normal forces and hinge moment loads were overpredicted by the analysis, confirming that the interface structure maintained additional margin in structural strength.

- The analysis-predicted interface reaction loads compare reasonably well to the reaction loads observed in flight, validating the finite element models used for calculating the individual interface fitting reaction loads.

- Normal force and hinge moment loads measured from the static pressure sensors located on the flap surface compared well to the calibrated strain-gage loads and can provide additional insight into the external air loads acting on the flap.

The ACTE interface loads into the wing were successfully monitored in real time in flight, allowing the safe expansion of the ACTE flight envelope. The work presented in this paper is a first step in assessing the performance of the ACTE technology and validating the tools required for predicting the in-flight loads. 


\section{Acknowledgements}

The authors gratefully acknowledge the work performed by Andrew Holguin in planning and executing the load calibration of the interface fittings. The authors also acknowledge Christian Garcia for providing the STAR-CCM $+{ }^{\circledR}$ CFD solutions and Aliyah Ali for providing the flap pressure coefficient $(\mathrm{Cp})$ flight pressure data. The work from Christine Olson in calculating loads from the $\mathrm{Cp}$ data is also greatly appreciated. As well, the authors extend thanks to everyone in the Flight Loads Laboratory who assisted with the ACTE instrumentation installation and calibration of the interface fittings.

\section{References}

${ }^{1}$ Baumann, E., Hernandez, J., and Ruhf, J., “An Overview of NASA's SubsoniC Research Aircraft Testbed (SCRAT)," AIAA-2013-5083, 2013.

${ }^{2}$ Miller, E. J., Lokos, W. A., Cruz, J., Crampton, G., Stephens, C. A., Kota, S., Ervin, G., and Flick, P., "Approach for Structurally Clearing an Adaptive Compliant Trailing Edge Flap for Flight," 46th Society of Flight Test Engineers (SFTE) International Symposium, Lancaster, California, 2015.

${ }^{3}$ Kota, S., Osborn, R., Ervin, G., Maric, D., Flick, P., and Paul, D., "Mission Adaptive Compliant Wing - Design, Fabrication and Flight Test," RTO-MP-AVT-168, 2009.

${ }^{4}$ Gilyard, G., and Espana, M., "On the Use of Controls for Subsonic Transport Performance Improvement: Overview and Future Directions," NASA TM-4605, 1994.

${ }^{5}$ Kota, S., "Shape-Shifting Things to Come," Scientific American, May 2014, pp. 58-65.

${ }^{6}$ Hetrick, J. A., Osborn, R. F., Kota, S., Flick, P. M., and Paul, D. B., "Flight Testing of Mission Adaptive Compliant Wing," AIAA 2007-1709, 2007.

${ }^{7}$ Miller, E. J., Holguin, A. C., Cruz, J., and Lokos, W. A., "Strain Gage Load Calibration of the Wing Interface Fittings for the Adaptive Compliant Trailing Edge Flap Flight Test," AIAA-2017-0277, 2014.

${ }^{8}$ Skopinski, T. H, Aiken, W. S. Jr., and Huston, W. B., "Calibration of Strain-Gage Installations in Aircraft Structures for the Measurement of Flight Loads," NACA Report 1178, 1954.

${ }^{9}$ Jenkins, J. M., and DeAngelis, V. M., "A Summary of Numerous Strain-Gage Load Calibrations on Aircraft Wings and Tails in a Technological Format," NASA TM-4804, 1997.

${ }^{10}$ Murray, W. M, and Miller, W. R., The Bonded Electrical Resistance Strain Gage, an Introduction, Oxford University Press, New York, 1992, pp. 337-359.

${ }^{11}$ Ulbrich, N., and Volden, T., "Development of a New Software Tool for Balance Calibration Analysis," AIAA-2006-3434, 2006.

${ }^{12}$ Cmarc Personal Simulation Works, http://www.aerologic.com/cmarc [cited 2 November 2015].

${ }^{13}$ TRANAIR++, CALMAR Research Corporation, http://www.calmarresearch.com/NF/STG/Tranair/Tranair.htm [cited 2 November 2015].

${ }^{14}$ STAR-CCM+ ${ }^{\circledR}$, CD-adapco, http://www.cd-adapco.com [cited 2 November 2015].

${ }^{15}$ MSC Nastran, MSC Software Corporation, http://www.mscsoftware.com/product/msc-nastran [cited 2 November 2015].

${ }^{16}$ ANSYS, ANSYS, Inc., http://www.ansys.com/?gclid=CNic5Cb13cYCFYM9aQodmP8MRA [cited 2 November 2015]. 


\section{FIGURES}

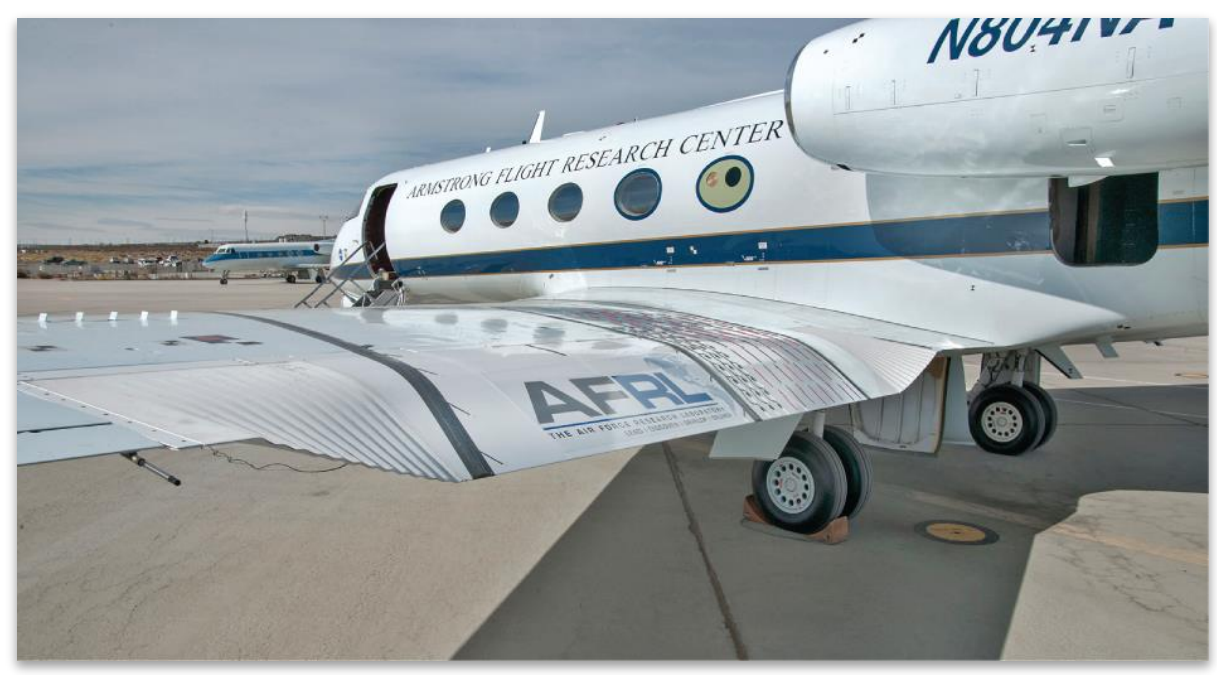

Figure 1. The Adaptive Compliant Trailing Edge flaps installed on the Gulfstream III SubsoniC Research Aircraft Testbed at a flap deflection of $20^{\circ}$.

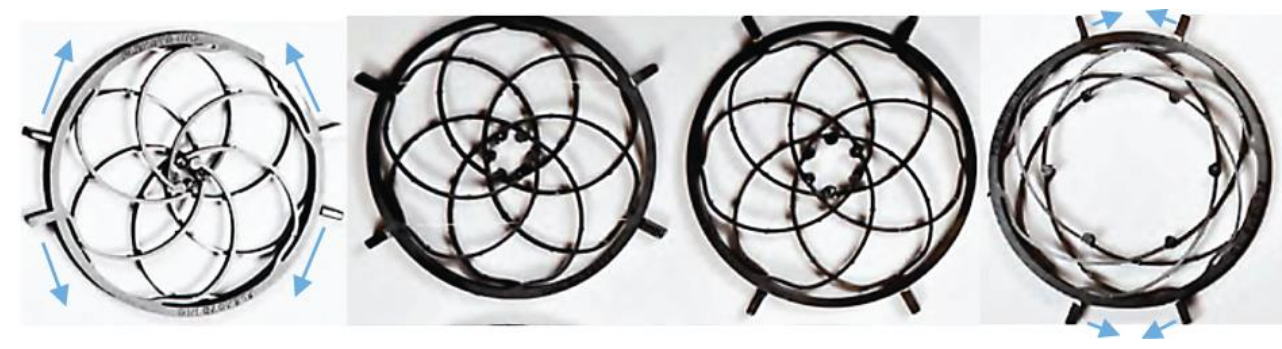

Figure 2. Example of a compliant iris mechanism.

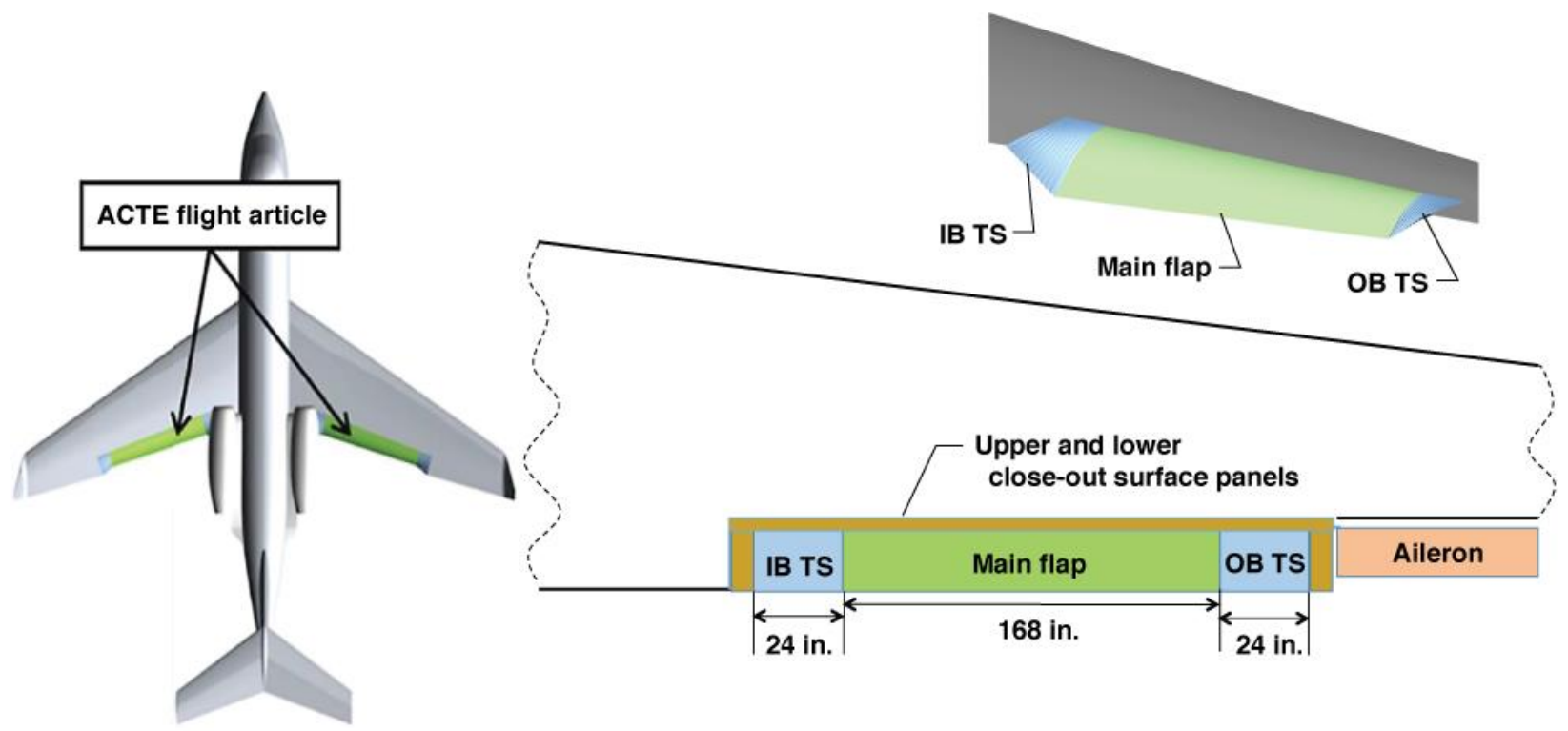

Figure 3. The primary components of the Adaptive Compliant Trailing Edge structure. 


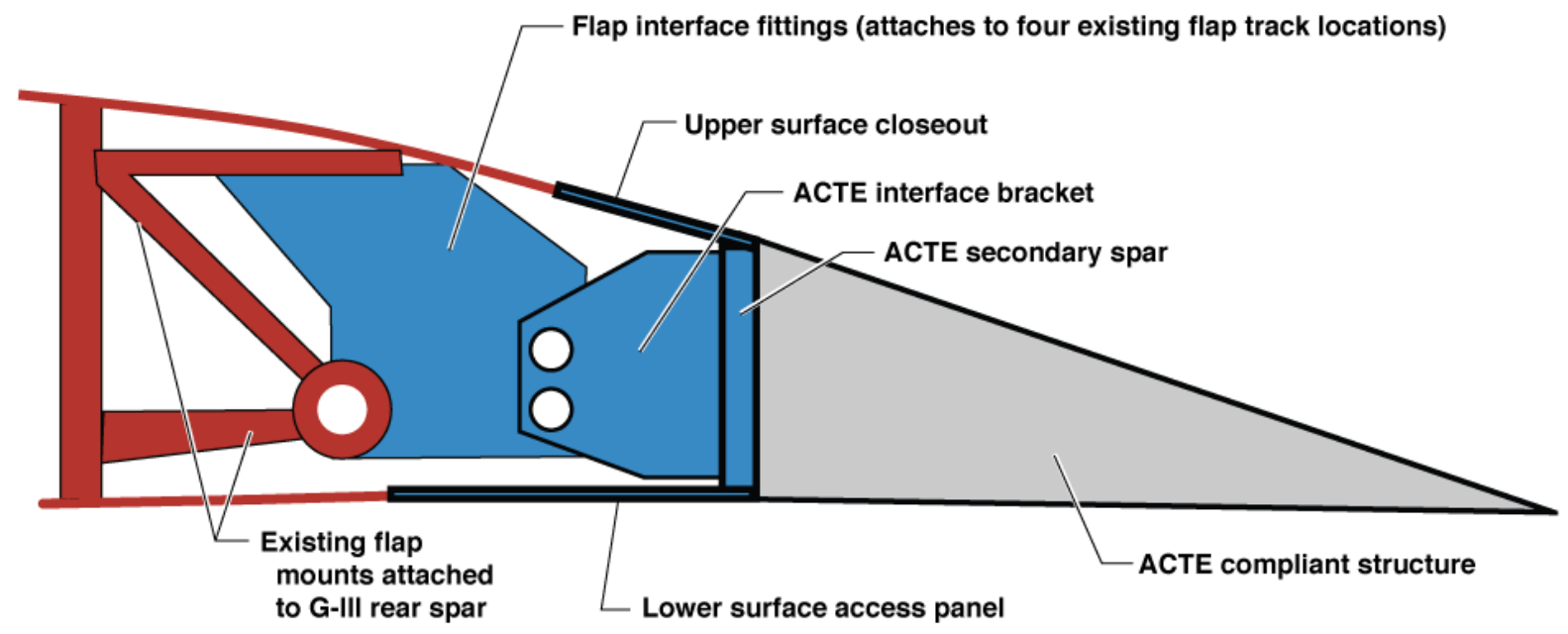

Figure 4. The interface attachment structure of the Adaptive Compliant Trailing Edge.

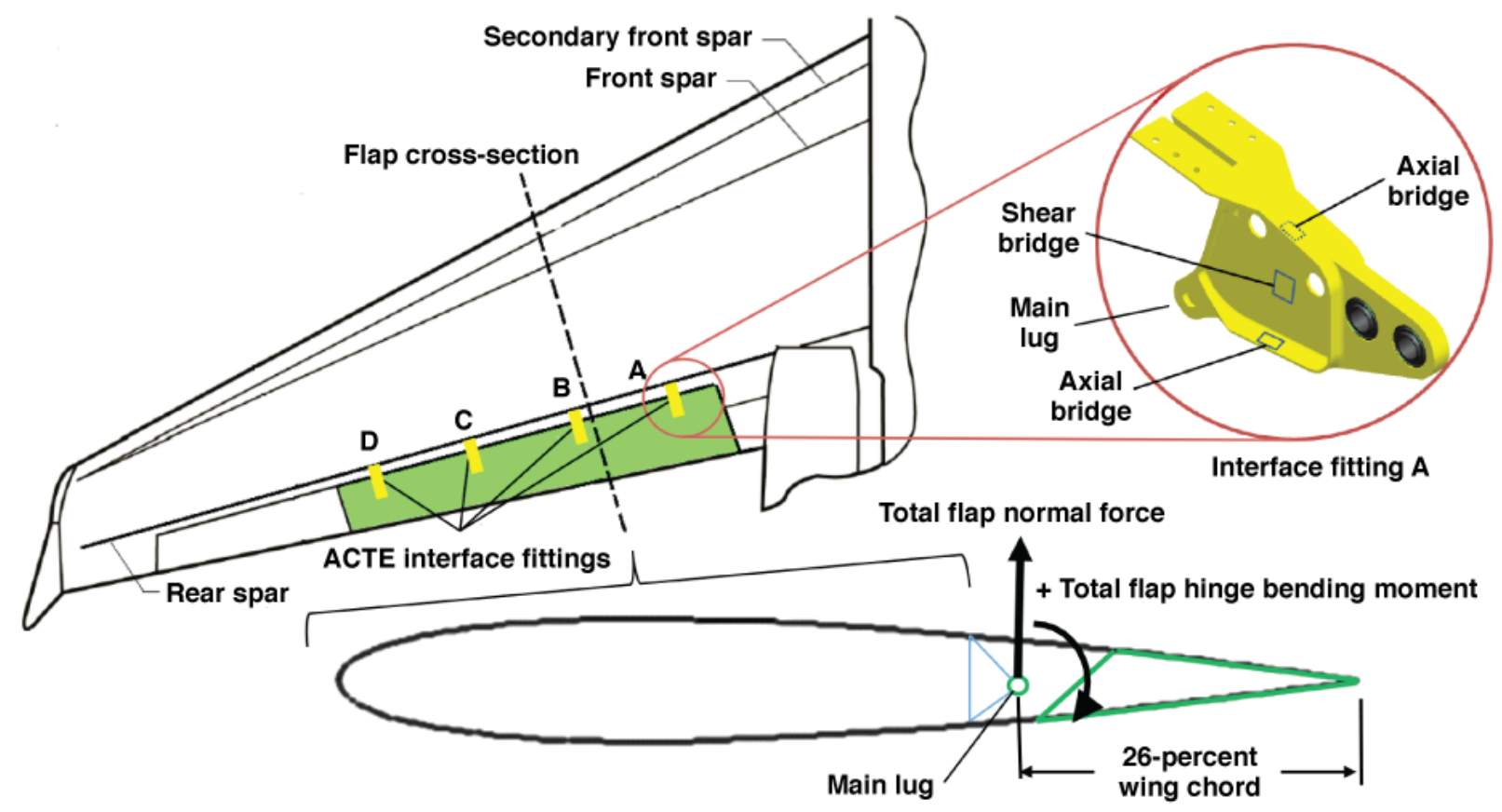

Figure 5. The interface fittings and hinge moment and normal force load coordinates of the Adaptive Compliant Trailing Edge structure. 


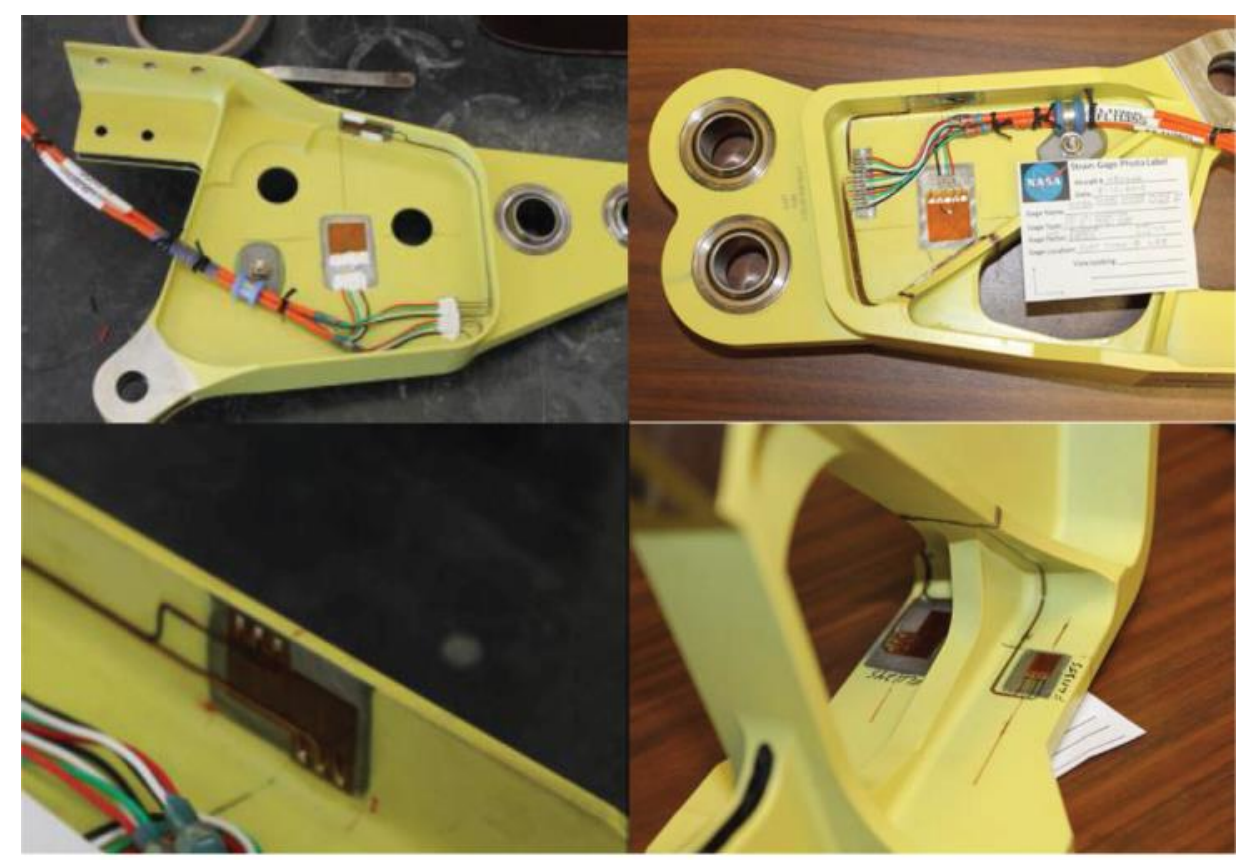

Fitting A

Fitting B

Figure 6. Instrumented wing interface fittings.

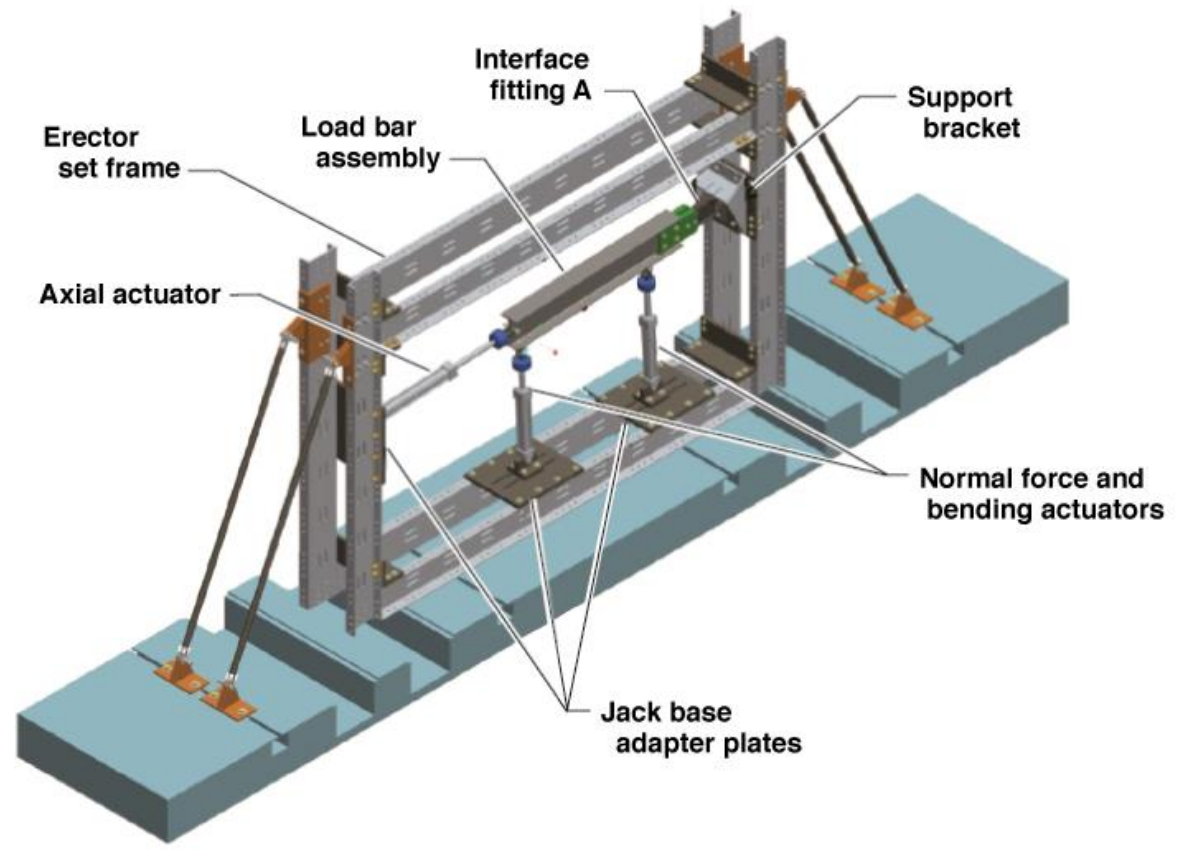

Figure 7. The interface fitting load calibration reaction frame for the Adaptive Compliant Trailing Edge. 

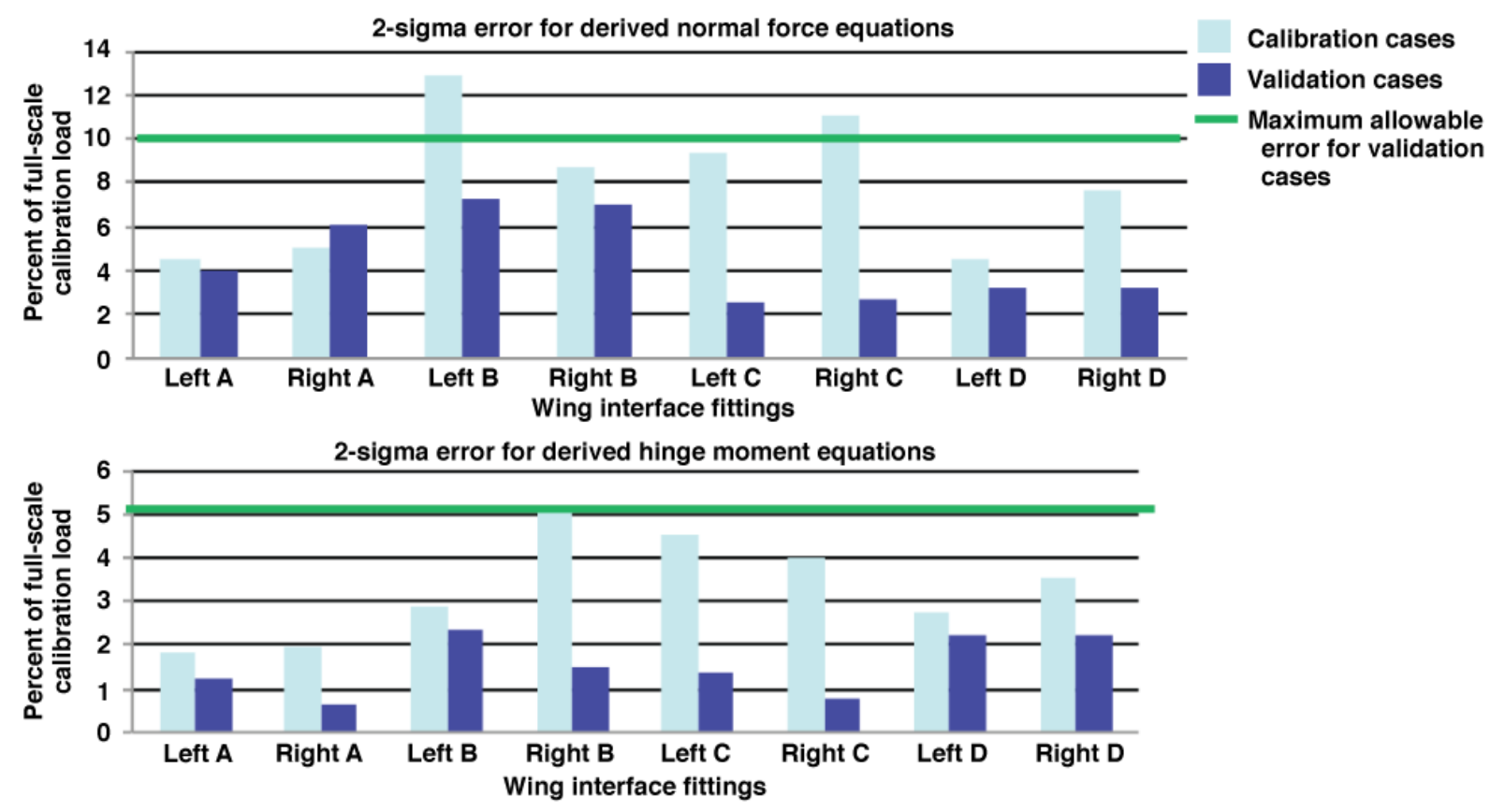

Figure 8. Interface fitting 2-sigma load equation errors for the Adaptive Compliant Trailing Edge.

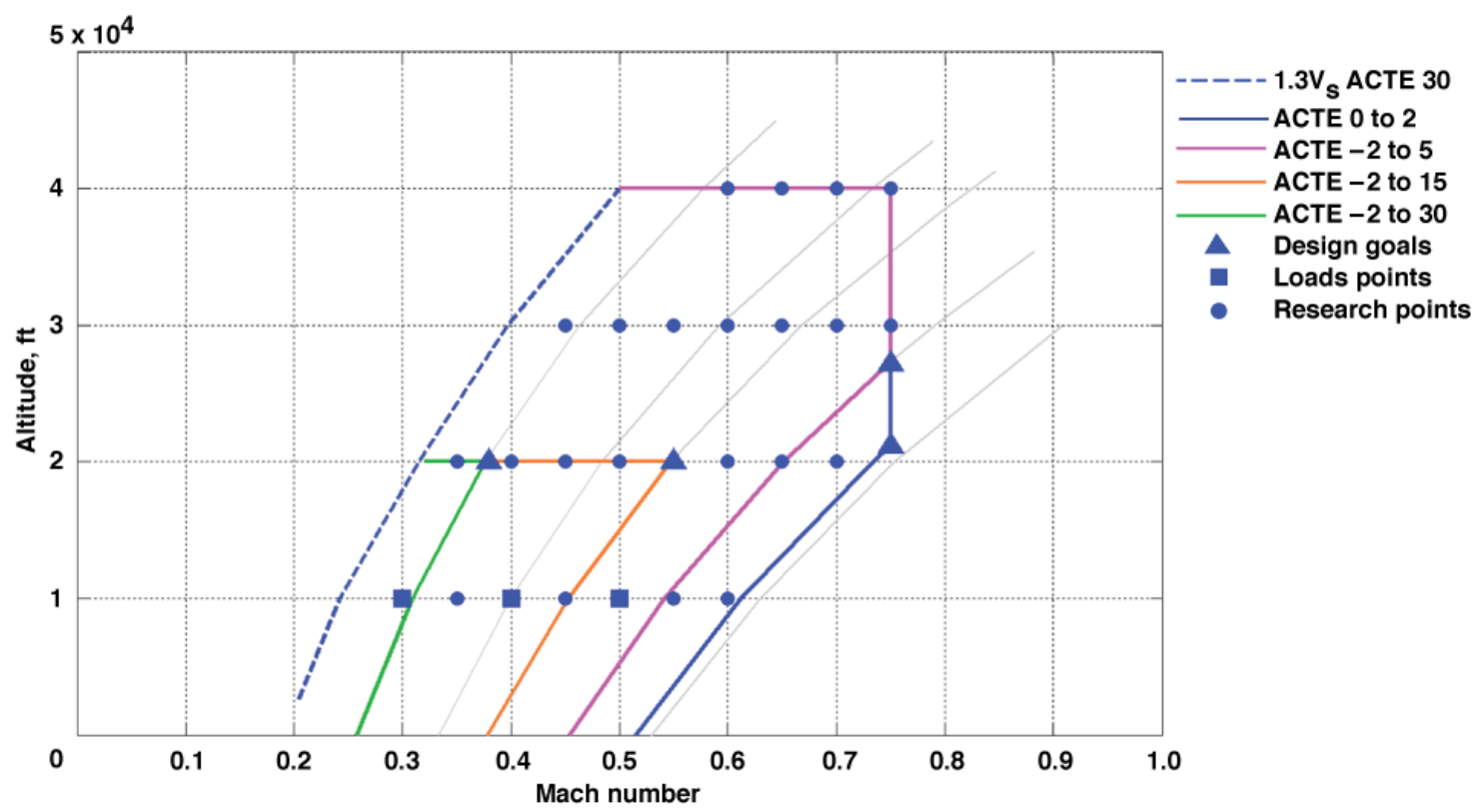

Figure 9. The flight envelope of the Adaptive Compliant Trailing Edge, with corresponding Mach limits for each set of flap positions. 


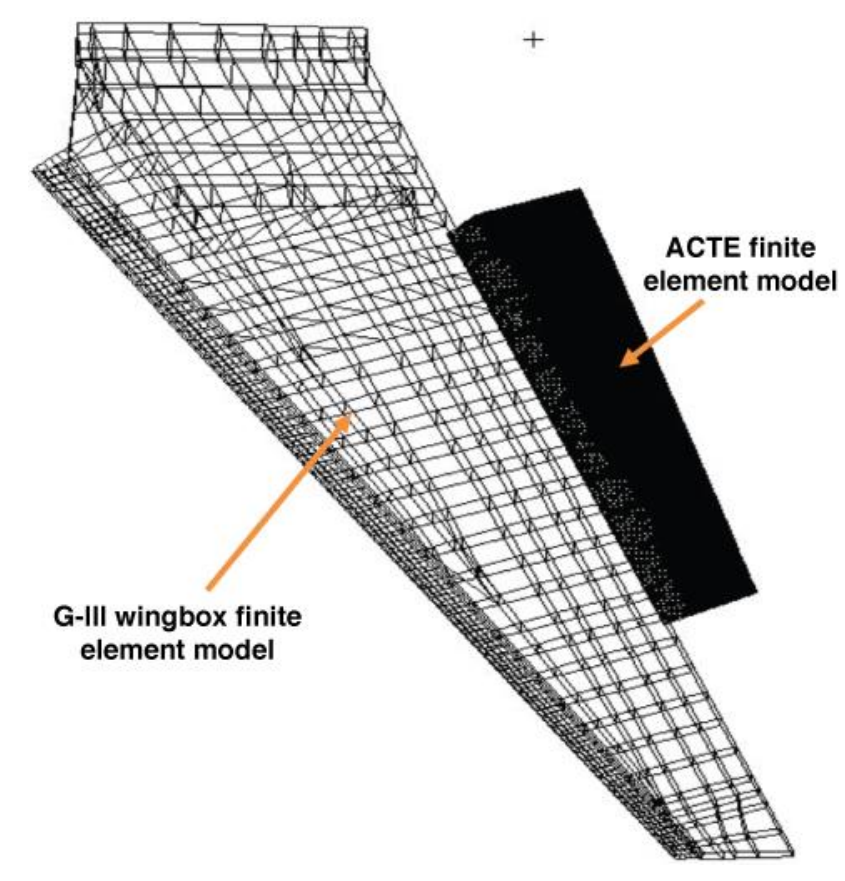

Figure 10. The finite element model of the Gulfstream III wingbox and the ACTE.

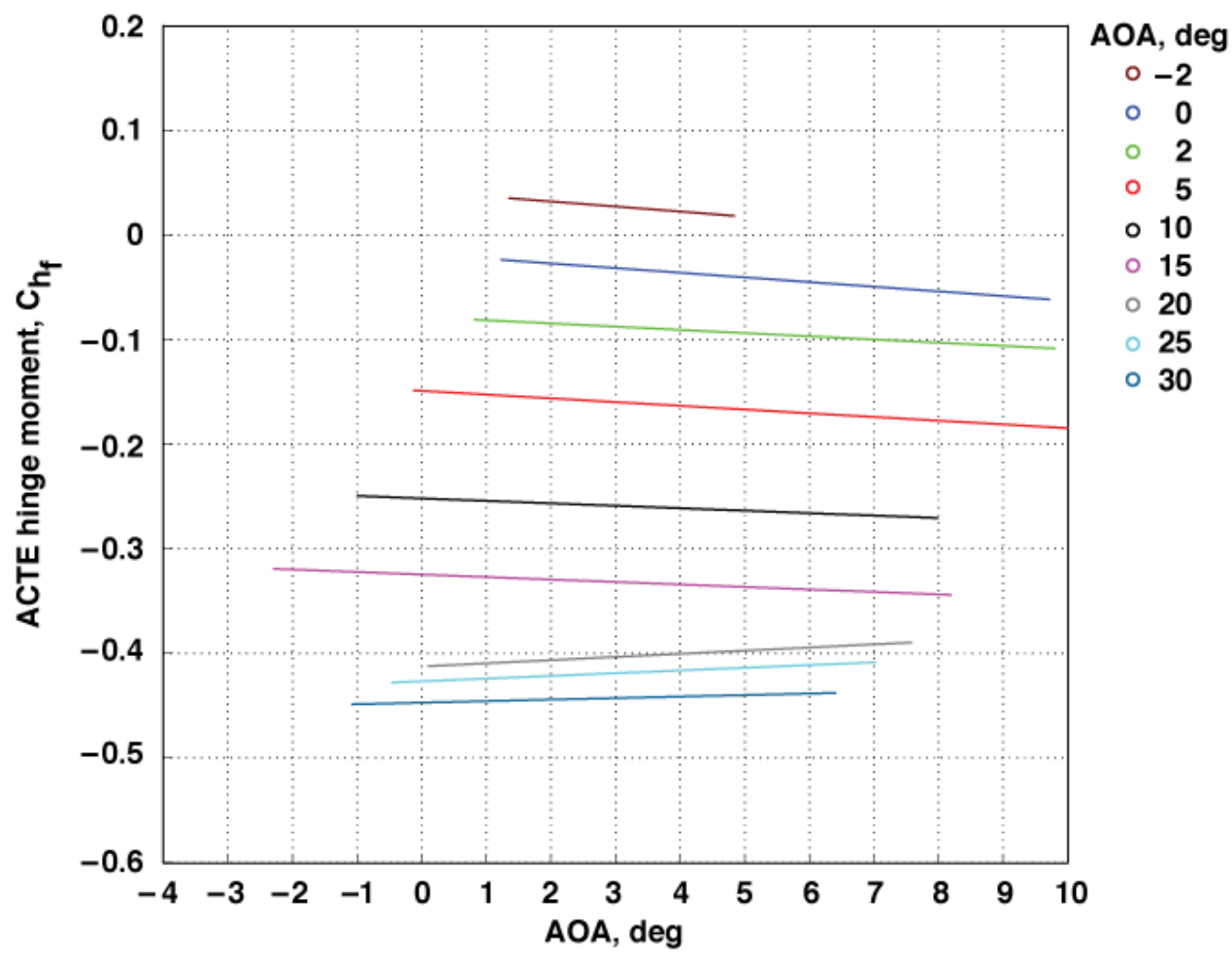

Figure 11. Flap interface hinge moment loads versus angle of attack for WUTs and POPUs at Mach numbers 0.3 and 0.4 and an altitude of $10,000 \mathrm{ft}$. 


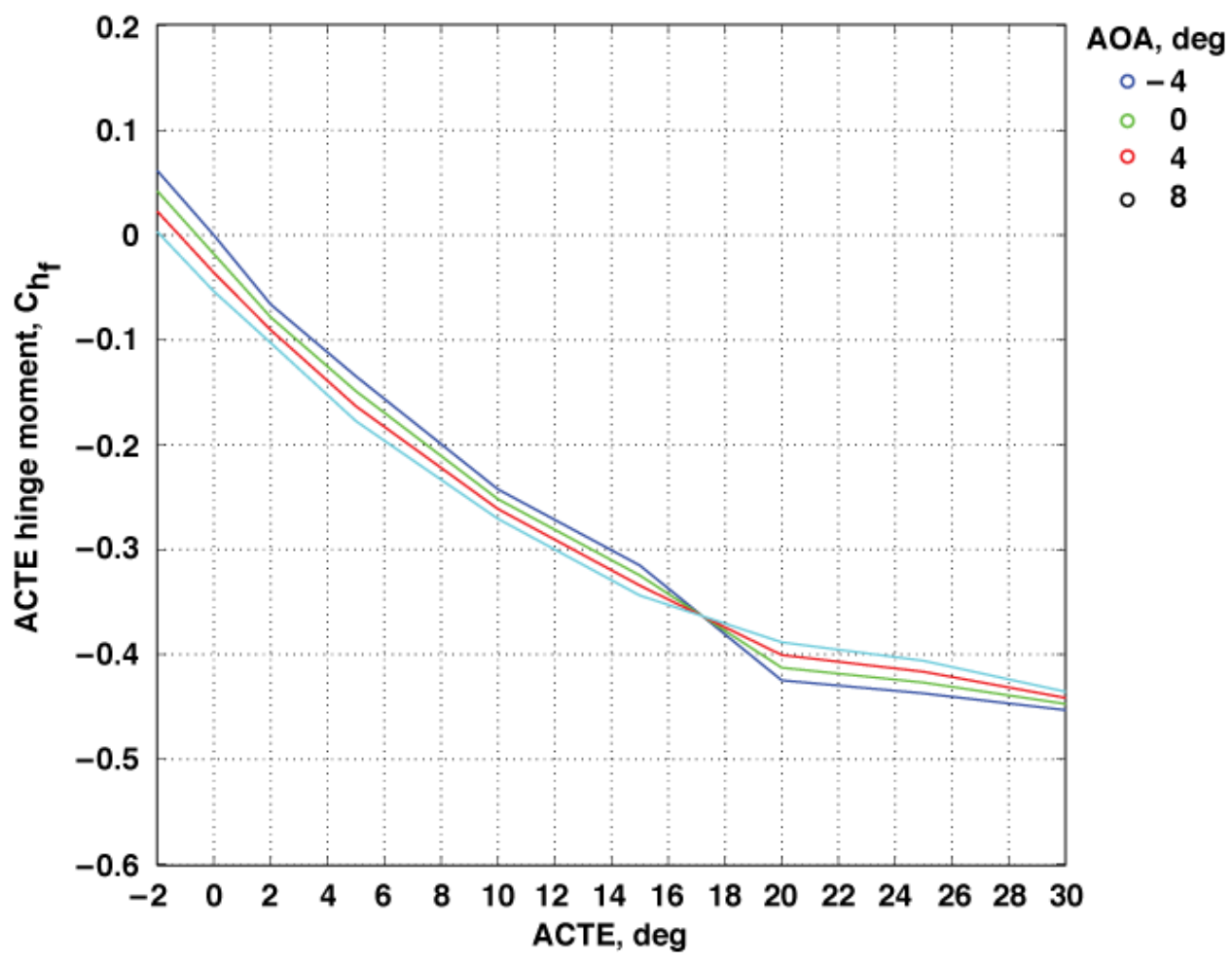

Figure 12. Hinge moment coefficient versus Adaptive Compliant Trailing Edge flap deflection for four different angles of attack.

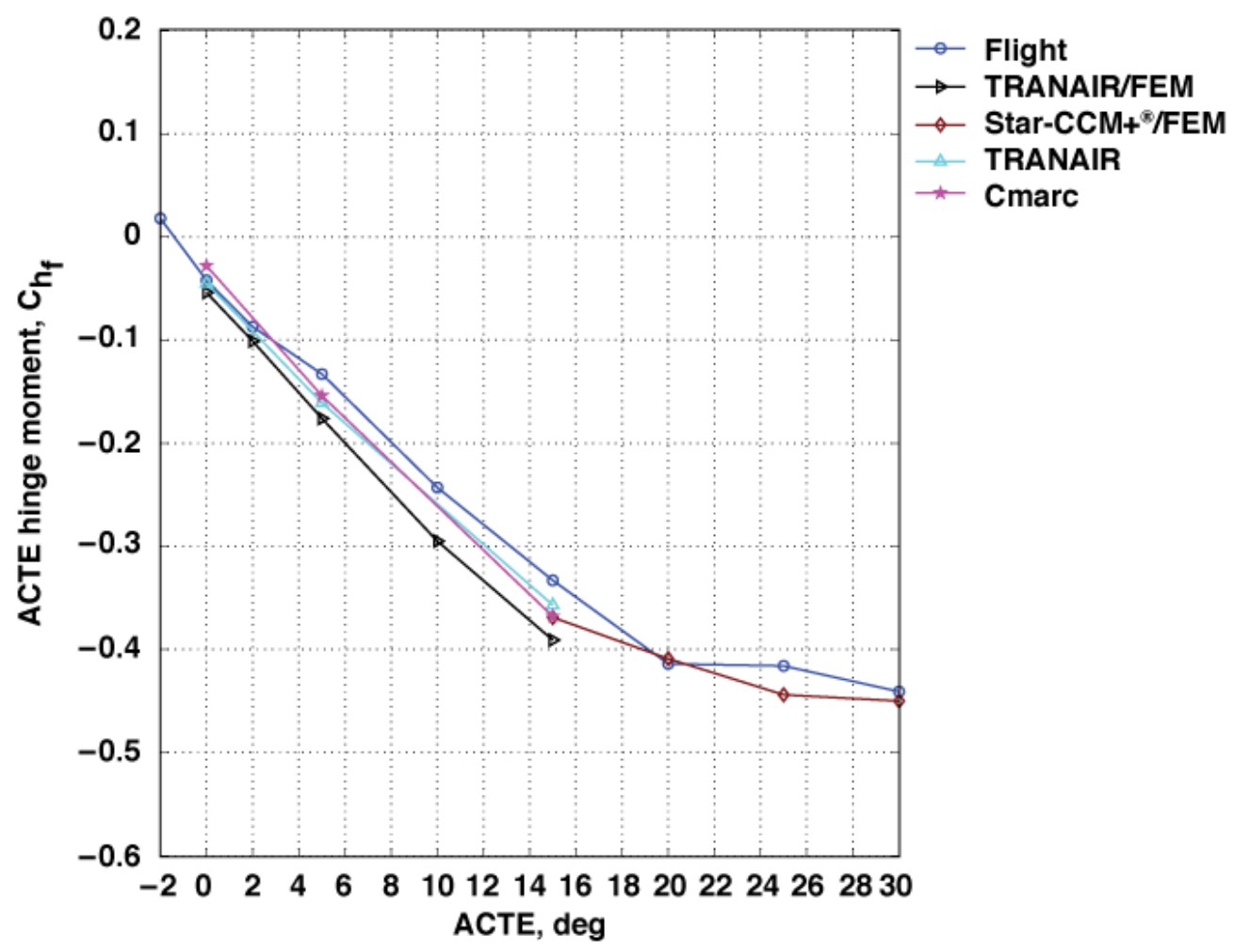

Figure 13. Analysis predictions for hinge moment loads versus flight hinge moment loads for equivalent flight conditions. 


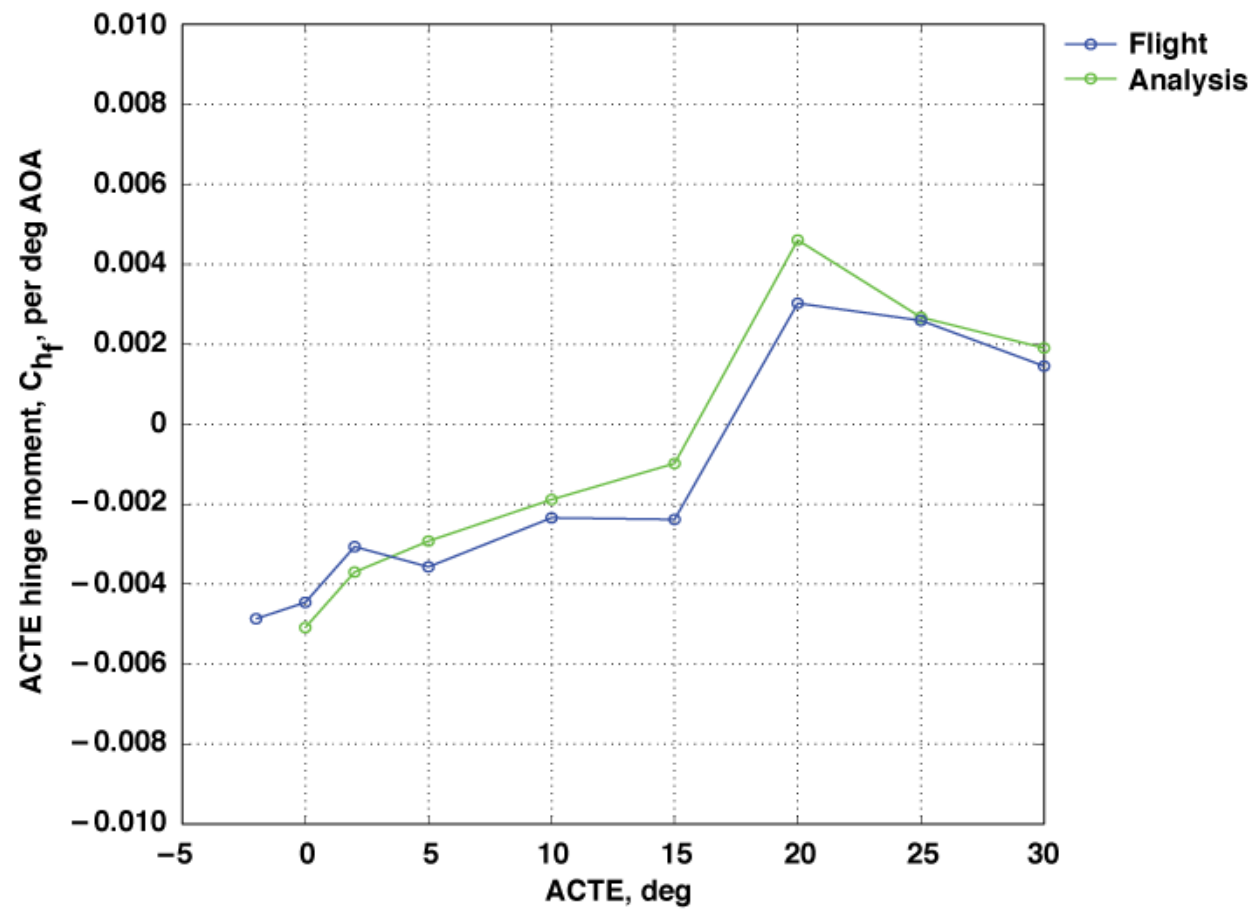

Figure 14. Hinge moment per degree of angle of attack for analysis conditions and equivalent flight conditions.

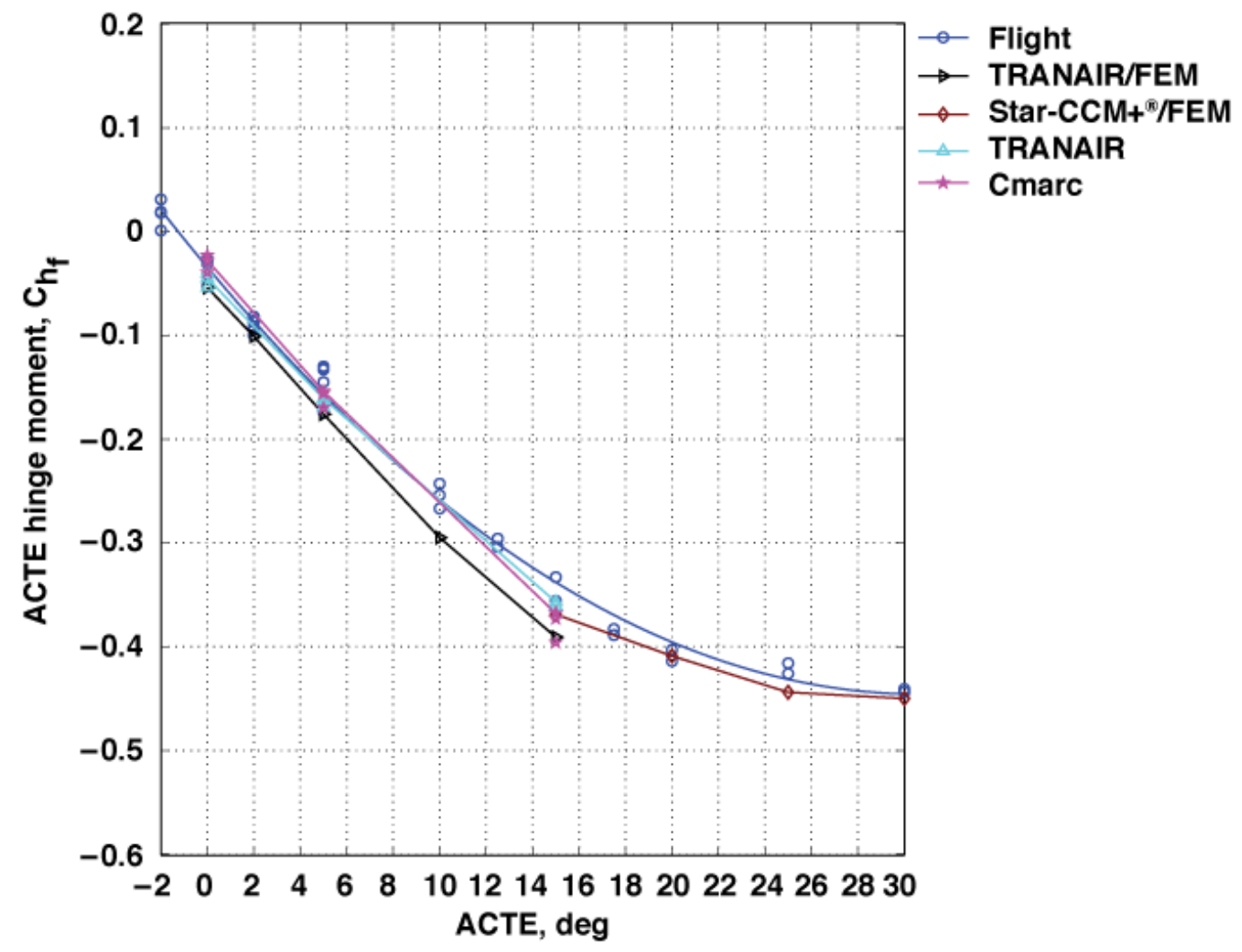

Figure 15. Hinge moment coefficient versus flap deflection comparison with analysis for all conditions listed in Table 3. 


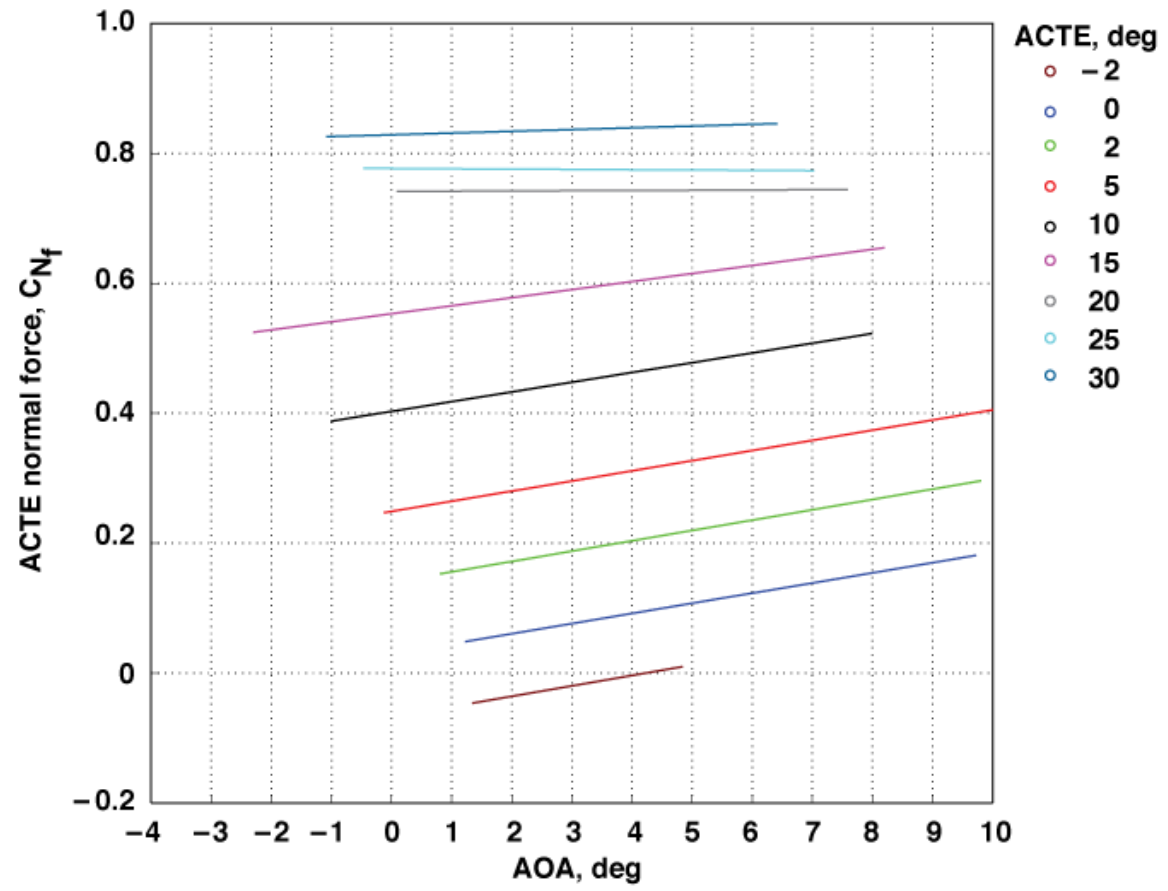

Figure 16. Normal force loads versus angle of attack for WUTs and POPUs at Mach numbers 0.3 and 0.4 and an altitude of $10,000 \mathrm{ft}$.

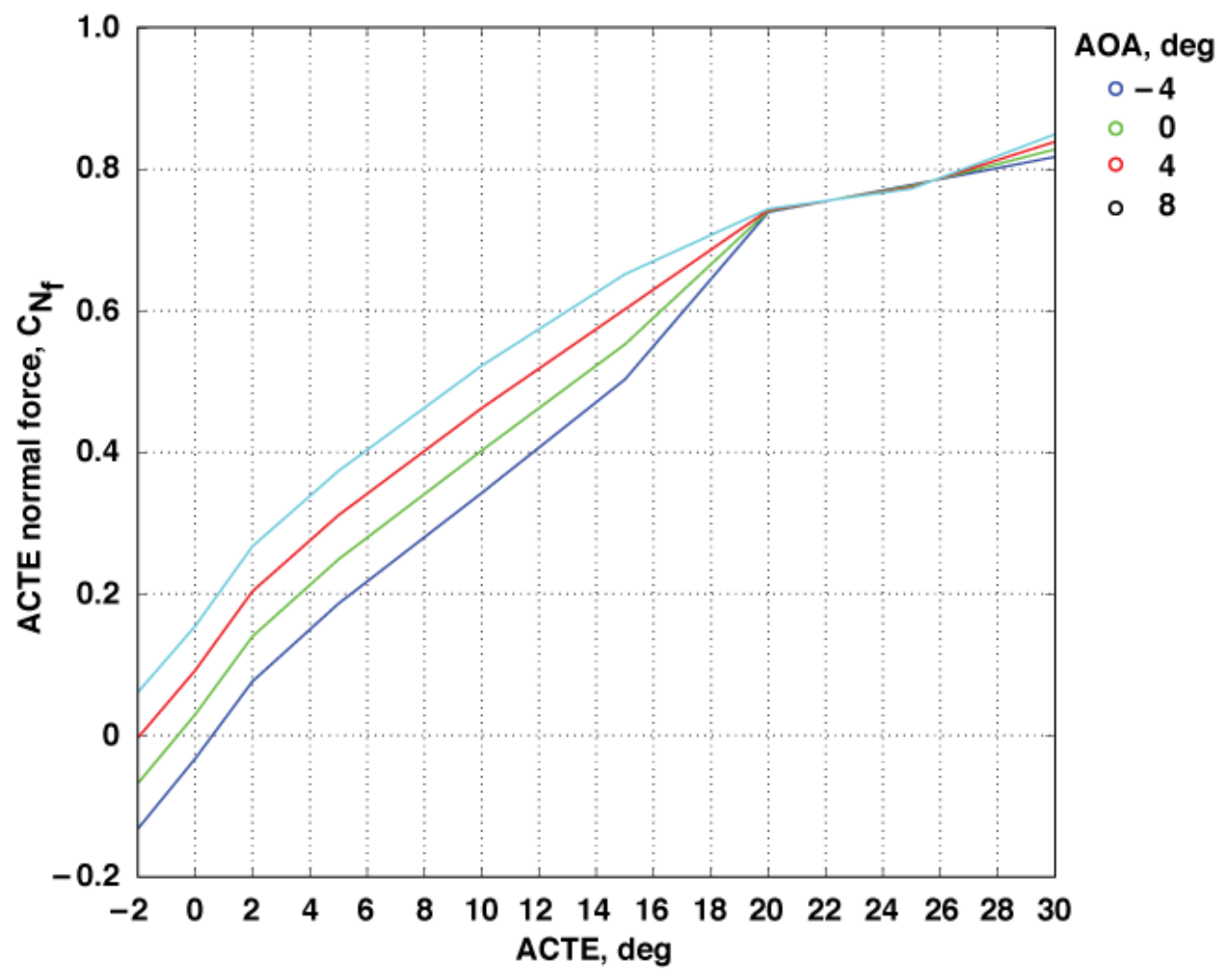

Figure 17. Normal force coefficient versus flap deflection for WUTs and POPUs at Mach numbers 0.3 and 0.4 and an altitude of $10,000 \mathrm{ft}$. 


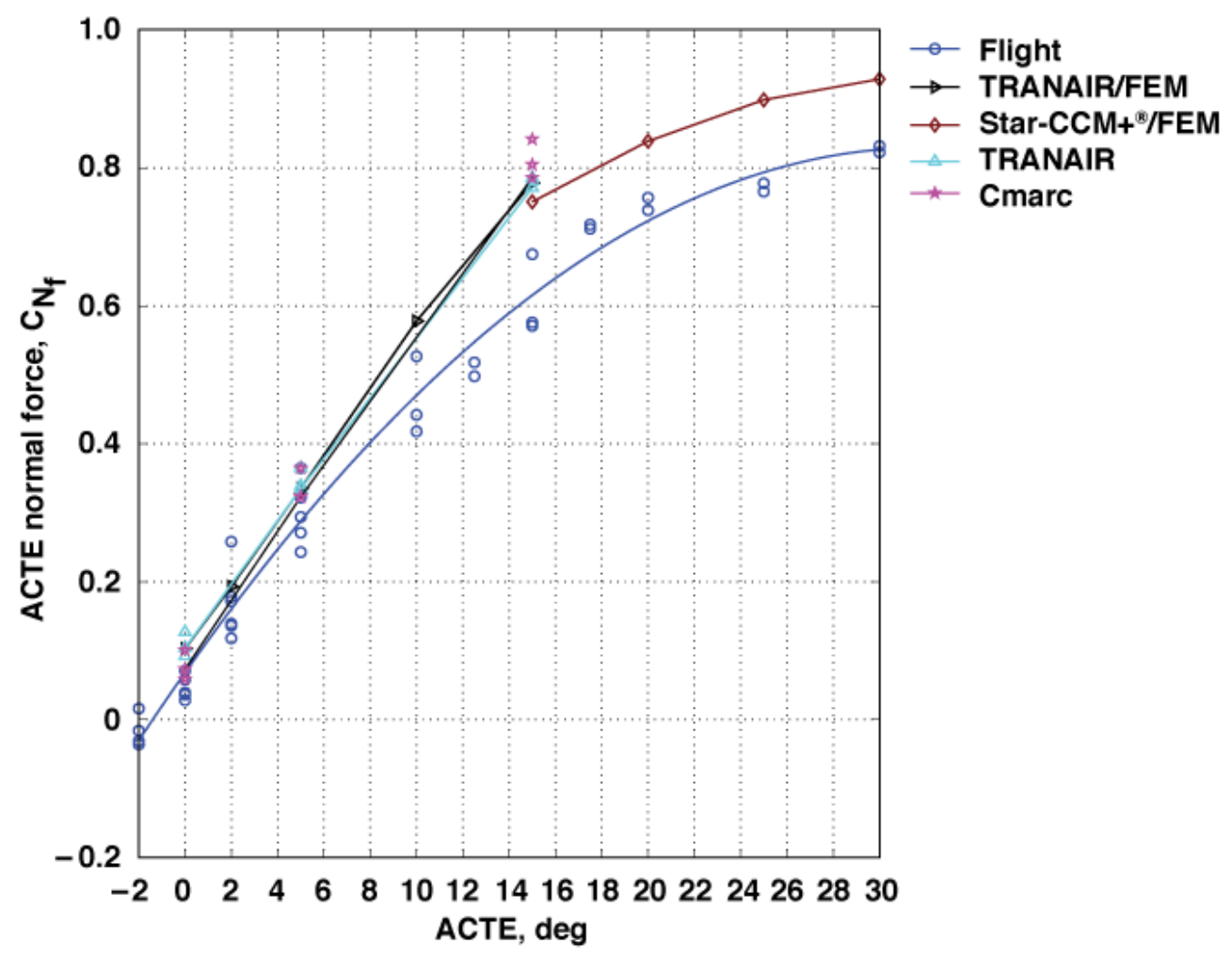

Figure 18. Normal force loads versus deflection comparison with analysis for all conditions listed in Table 3.

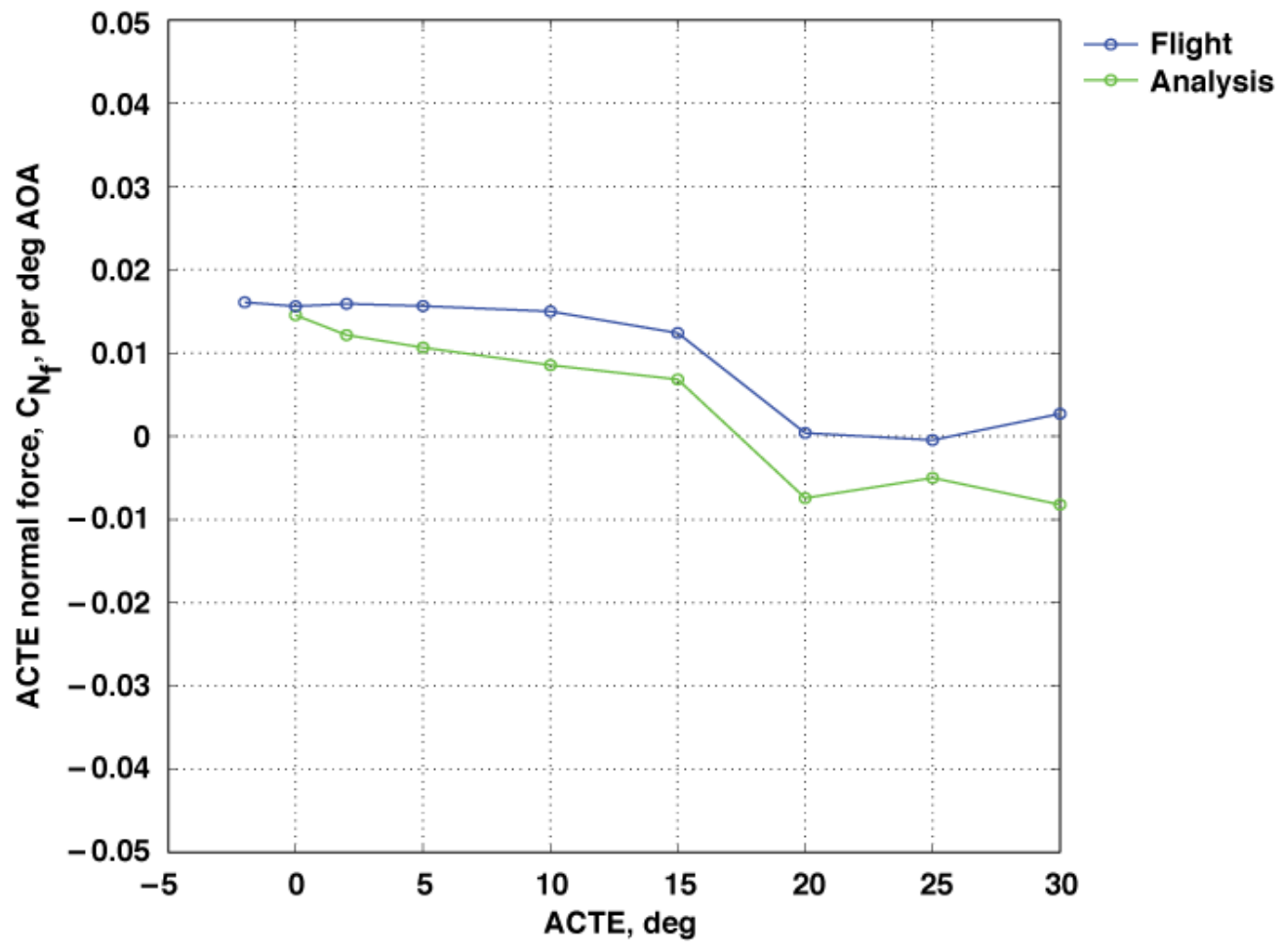

Figure 19. Slopes of the normal force coefficient per degree of angle of attack for WUTs and POPUs at Mach numbers 0.3 and 0.4 and an altitude of $10,000 \mathrm{ft}$. 

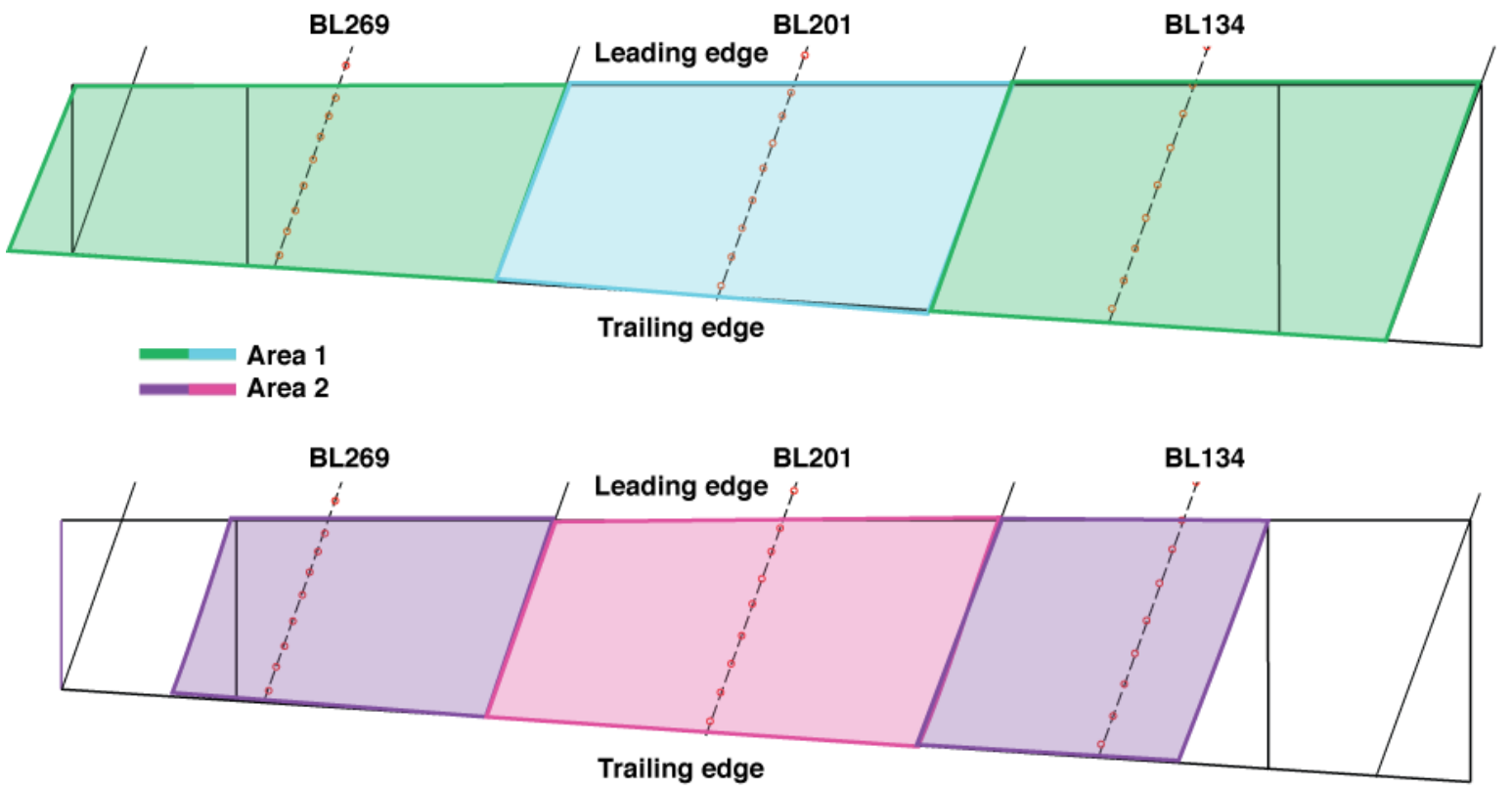

Figure 20. Adaptive Compliant Trailing Edge interface normal force and hinge moment pressure area definitions.

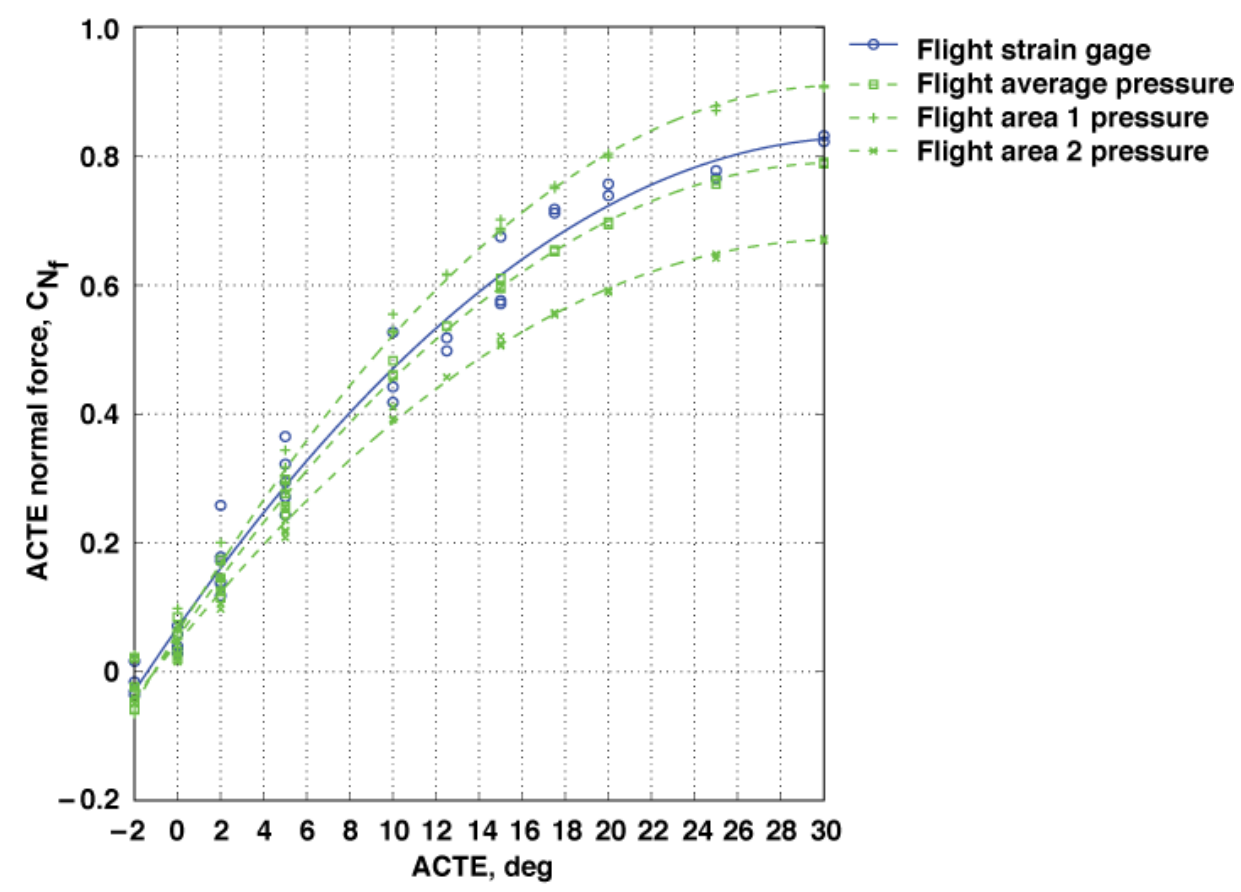

Figure 21. Normal force pressure and strain-gage comparison for all flight conditions listed in Table 3. 


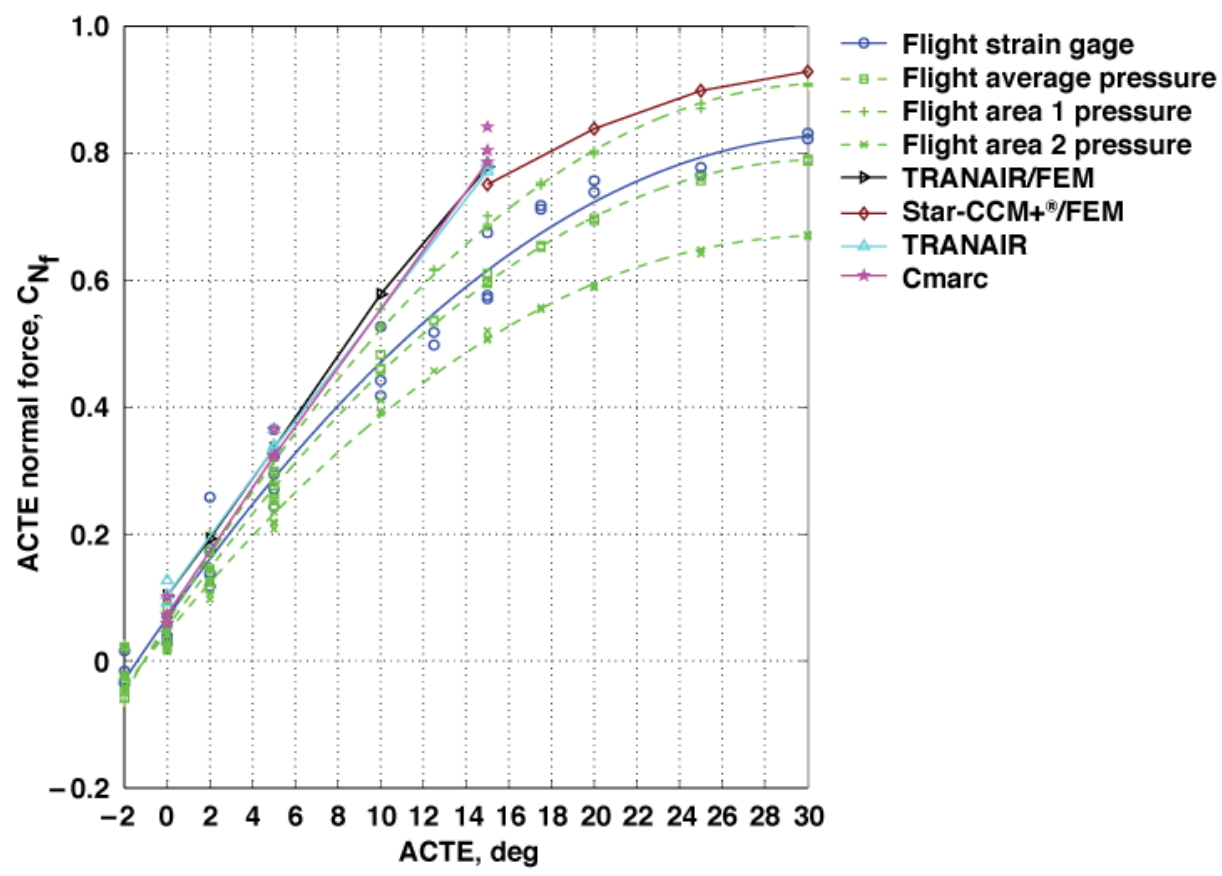

Figure 22. Normal force pressure and strain-gage comparison with analysis for all flight conditions listed in Table 3.

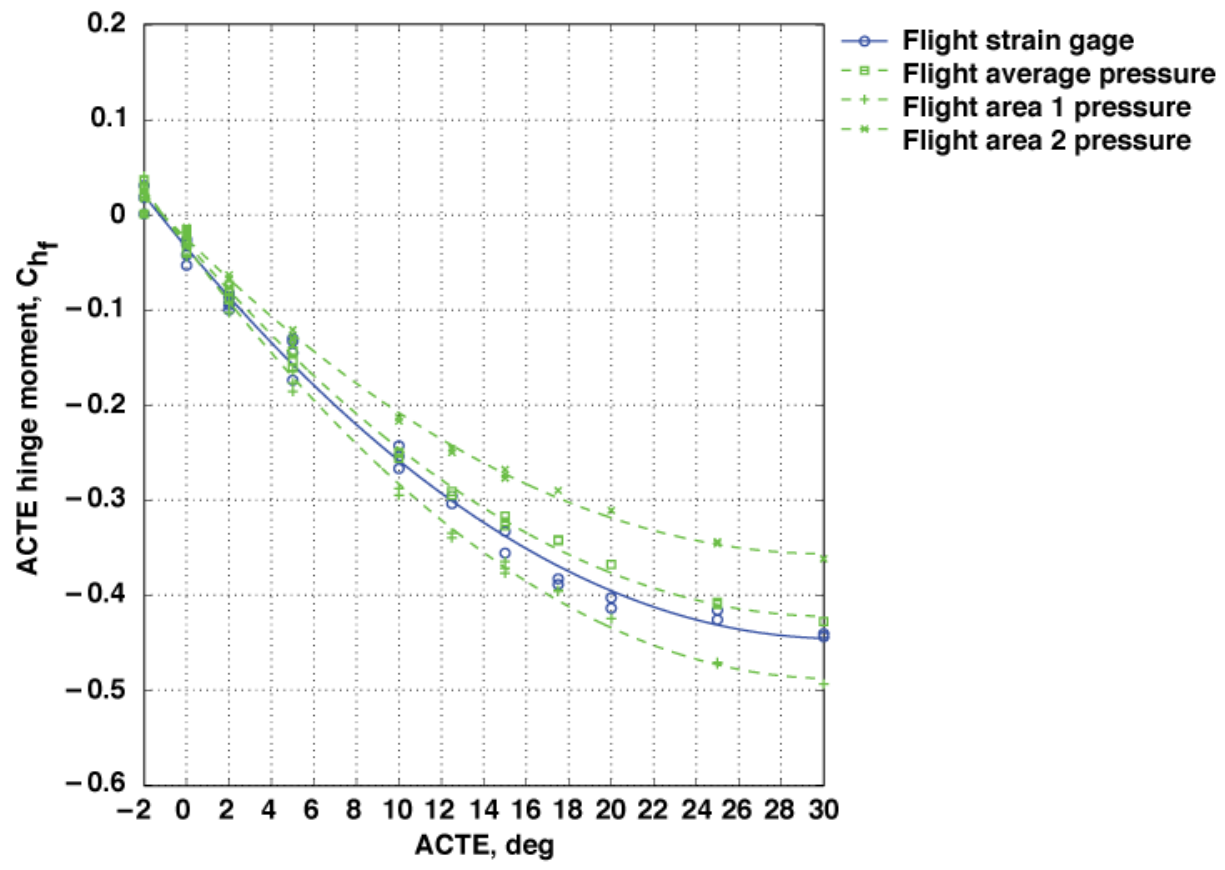

Figure 23. Hinge moment pressure and strain-gage comparison for all flight conditions listed in Table 3. 


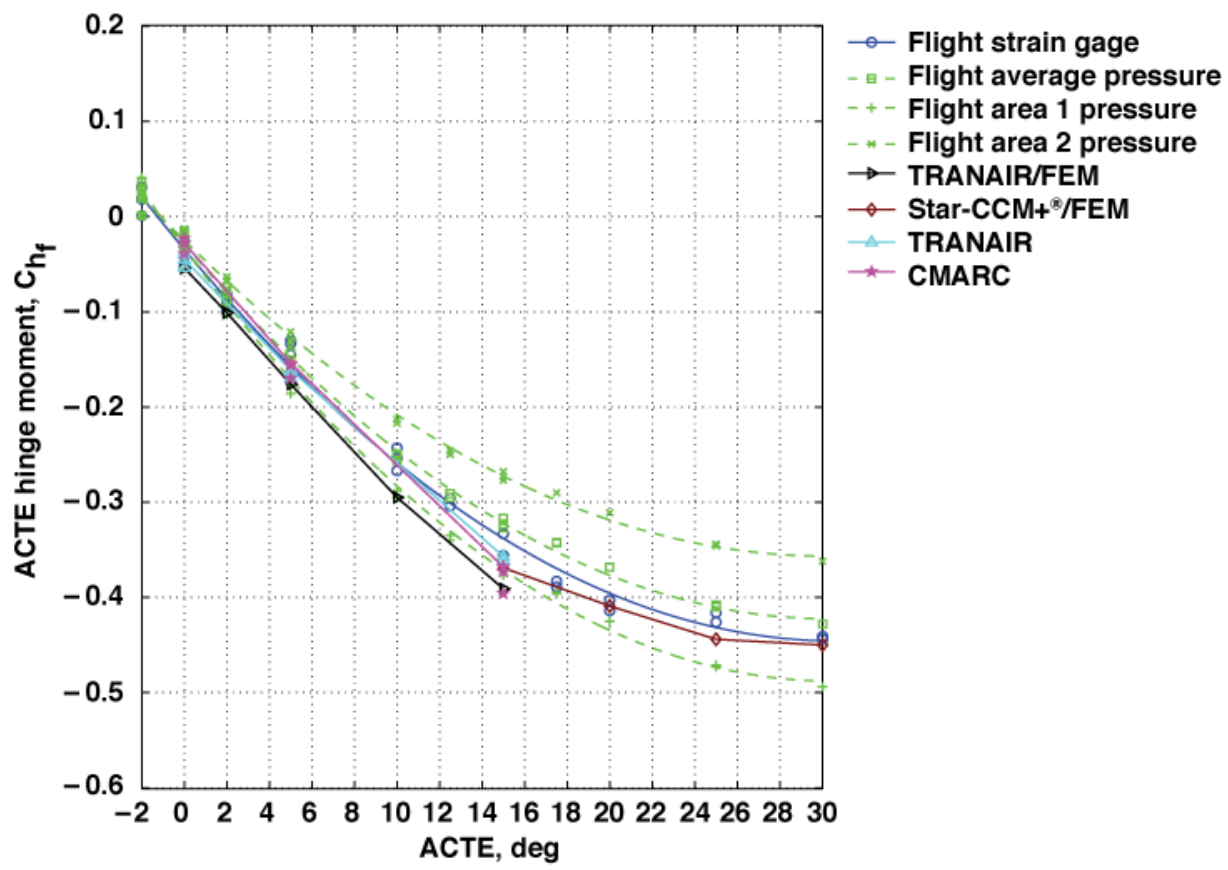

Figure 24. Hinge moment pressure and strain-gage comparison with analysis for all flight conditions listed in Table 3. 